\title{
Phosphazene/Triisobutylaluminum-Promoted Anionic Ring- Opening Polymerization of 1,2-Epoxybutane Initiated by Secondary Carbamates
}

\author{
L. Hassouna, ${ }^{a}$ N. Illy*a and P. Guégan ${ }^{a}$ \\ Attempts to use carbamate-phosphazene base as initiating systems for the polymerization of 1,2-epoxybutane were \\ unsuccessful. As a matter of fact, carbamate deprotonation by phosphazene bases led to their fast decomposition \\ generating alkoxide anions which initiate the polymerization rather than carbamate anions. Conversely, in the presence of \\ triisobutylaluminum -a Lewis acid- the in situ generation of an anionic initiator $X$ - obtained by the deprotonation of with \\ $t \mathrm{BuP}_{4}$ phosphazene base was tested as possible way to initiate the polymerization of 1,2-epoxybutane. A particular \\ attention was given to the detection of eventual transfer or side-reactions according to the \\ carbamate:triisobutylaluminum:phosphazene base ratio, to the solvent dielectric constant and to the number of $\mathrm{P}=\mathrm{N}$ - \\ units in the phosphazene base. Reaction performed with the stoichiometric ratio (1:1:1) of \\ carbamate:triisobutylaluminum:tBuP 2 , gave the best results. Under these conditions, the initiation of the polymerization \\ by the carbamate anion was quantitative; no transfer reactions have been observed and the polymerization proceeded in \\ a controlled manner to afford amide end-capped poly(butylene oxide) with narrow molar mass distribution and expected \\ molar masses.
}

\section{Introduction}

The controlled synthesis of complex macromolecular architectures remains one of the most appealing topics in polymer chemistry. In particular, metal-free polymerization techniques provide new opportunities in the field, such as extending the range of functional groups that can be used as polymerization initiators. In this context, phosphazene bases are a very powerful and versatile tool. ${ }^{1}$ These "superbases" are able to deprotonate low acidic molecules, generating extremely reactive anions which can be used as initiator for anionic polymerizations: e.g. monofunctional alcohols ${ }^{2}$ (methanol, ${ }^{3}$ solketal, ${ }^{4}$ 4-phenyl-2-butanol, 2-methyl-1-phenyl2-propanol ${ }^{5}$, 3-phenyl-1-propanol, $, 6,7$ terpene, $\left.^{8}(\text { p-cresol, })^{9}\right)$; polyfunctional alcohol (glycerol, ${ }^{10}$ ethylene glycol, ${ }^{3}$ tris(hydroxymethyl)propane, ${ }^{6}$

$1,2,4,5$ benzenetetramethanol ${ }^{11}$ ); phenol; $^{12}$ thiols (Thiophenol, ${ }^{13}$ furfuryl mercaptan ${ }^{14}$ ); $\mathrm{CH}$-acidic compounds like di-alkyl malonate, ${ }^{12}$ ethyl acetate $^{3}$ or $\alpha$-methylbenzyl cyanide; ${ }^{9} \mathrm{NH}-$ acidic compounds like carbazole; ${ }^{12}$ carboxylic acids (MeO-PEG$\mathrm{COOH},{ }^{15}$ 1-pyreneacetic acid $\left.^{16}\right)$. For the most part, these

a. Sorbonne Universités, UPMC Univ Paris 6, CNRS, Institut Parisien de Chimie Moléculaire, Equipe Chimie des Polymères, 4 place Jussieu, F-75005 Paris, France. E-mail: nicolas.illy@upmc.fr

Electronic Supplementary Information (ESI) available: ${ }^{1} \mathrm{H}$ NMR spectra (runs 7, 9, 11 and 12), SEC traces (runs 7, 9 and 11) and MALDI-ToF spectra (runs 9 and 10). Additional experiment protocols with kinetic plots, MALDI-ToF spectra and SEC traces at various reaction times. precursors have been small molecules but polymer chain-ends (poly(propylene glycol), ${ }^{4}$ PEO $^{7}$ ) or polymer side-groups $\left(\right.$ starch $^{17}$ ) have also been considered. Lastly, the secondary amide groups, that are extremely weak acid, have led to an effective, efficient and quantitative initiation of the anionic ring-opening polymerization of oxiranes. ${ }^{18,19}$

Nevertheless, additional classes of initiators are still required to expand the diversity and complexity of architectures accessible by ROP methods. Carbamates are found in a large variety of biologically active compounds and are commonly found in drugs and prodrugs. ${ }^{20}$ Carbamate are also protective groups that have been extensively used in organic chemistry. ${ }^{21}$ Therefore, their functionalization is very attractive and many papers are dealing with their $\mathrm{N}$-alkylation ${ }^{22-25}$ or their $\mathrm{N}$ acylation. ${ }^{26}$ In addition, the carbamate bond (or urethane bond) are found in polyurethanes, which are very widespread polymers due to their excellent mechanical properties. For example, polyurethane polymers have been used in a wide range of biomedical applications ${ }^{27}$, building materials ${ }^{28}$ or textiles. ${ }^{29}$ They have also been chemically modified to introduce additional properties or to overcome some limitation such as in vivo degradation. In particular, graft PU have been synthesized, such as protein resistant PEO-graft$\mathrm{PU}^{30-32}$ or water-compatible poly(acrylic acid)-PU. ${ }^{33}$ Different synthetic strategies have been used to prepare graft-PU. Polymer-graft-PU are generally synthesized by reacting PU with diisocyanate in presence of a catalyst and then, coupling a preformed end functional polymer with a free isocyanate. ${ }^{31,} 32$ Nevertheless this "grafting to" approach has some drawbacks, 
such as the pre-treatment with diisocyanate. Moreover this method is better suited for conjugation of low molecular weights macromolecules. Zhou et al. used a "grafting through" strategy based on macroiniferter. ${ }^{30}$ A "grafting from" strategy has also been employed in a moderate number of research papers, in which controlled radical polymerization techniques have exclusively been used. ${ }^{33}$ However, this strategy often requires prior heavy chemical modifications to covalently attach a polymerization initiators to the polyurethane. Nevertheless, to the best of our knowledge, direct "grafting from" polymerization has never been performed on native polyurethane. Moreover, secondary carbamate moieties have never been directly used as polymerization initiators. Only few examples of primary carbamate salts used as polymerization initiators are reported in the literature. ${ }^{34,} 35$ Few carbamate pKa values appear in the literature. As the result of the presence of an additional electronegative oxygen atom, carbamate are expected to be slightly more acidic than amide groups: for instance in DMSO, the pKa of 2-oxazolidinone is 20.8 compared to $\mathbf{2 4 . 2}$ for 2-pyrrolidinone. ${ }^{36}$ According to our previous work using of amide group as initiator, carbamate deprotonation should be easy. However, carbamate anions are relatively unstable in the presence of strong bases. ${ }^{21}$ Thus, initiation kinetics versus degradation kinetics will be a key factor.

This publication reports an investigation on the use of carbamate as a new class of functional initiators for anionic ring-opening polymerization of 1,2-epoxybutane. The efficiency of the carbamate-phosphazene base initiating system was assessed in the absence or in the presence of Lewis acid. The resulting polymers have been fully characterized by NMR, SEC, and MALDI-ToF allowing the determination of initiation mechanisms. A particular attention was also given to the potential transfer reactions.

\section{Experimental}

\section{Materials.}

Phosphazene base $\mathrm{BBuP}_{4}$ solution $\left(0.8 \mathrm{~mol}^{\mathrm{L}} \mathrm{L}^{-1}\right.$ in hexane, Aldrich), Phosphazene base $t \mathrm{BuP}_{2}$ solution (2.0 mol. $\mathrm{L}^{-1}$ in THF, Aldrich), $\mathrm{CaH}_{2}$ (93\%, 0-2 mm grain size, Acros Organics), $\mathrm{N}$ methylurethane (Acros 99\%), $\mathrm{N}$-ethylurethane (Aldrich 99\%), tert-butyl $\mathrm{N}$-allylcarbamate (Aldrich 98\%), triisobutylaluminium (1.1 mol. $\mathrm{L}^{-1}$ solution in toluene, Acros) and acetic acid (99\%, Aldrich) were used as received. 1,2-epoxybutane (>99\%, Aldrich) was distilled over $\mathrm{CaH}_{2}$ two times prior use. Toluene and THF were dried with an MBRAUN MB SPS-800 solvent purification system under nitrogen.

\section{Instruments.}

${ }^{1} \mathrm{H}$ and ${ }^{13} \mathrm{C}$ NMR spectra were recorded in $\mathrm{CDCl}_{3}$ or $\mathrm{CD}_{3} \mathrm{COCD}_{3}$ using a Bruker $400 \mathrm{MHz}$ NMR spectrometer. Size Exclusion Chromatography Experiment (SEC) were carried out on three PL Gel Mixte C $5 \mu \mathrm{m}$ columns $(7,5 \times 300 \mathrm{~mm}$; separation limits: 0,2 to $2000 \mathrm{~kg} \cdot \mathrm{mol}^{-1}$ ) maintained at $40^{\circ} \mathrm{C}$ coupled with a solvent and sample delivery module Viscotek GPCmax and 2 modular detectors: a differential refractive index (RI) detector Viscoteck 3580 and a Diode Array UV Detector Shimadzu SPD20-AV. THF was used as the mobile phase at a flow rate of $1 \mathrm{~mL} \cdot \mathrm{min}^{-1}$, toluene was used as a flow rate marker. All polymers were injected $(50 \mu \mathrm{L})$ at a concentration of $5 \mathrm{mg} \cdot \mathrm{mL}^{-1}$ after filtration through a $0.45 \mu \mathrm{m}$ pore-size membrane. The OmniSEC 4.6.2 software was used for data acquisition and data analysis. The number-average molar masses $\left(\bar{M}_{\mathrm{n}}\right)$, the weightaverage molar masses $\left(\bar{M}_{\mathrm{w}}\right)$, and the molar mass distributions $\left(\Theta=\bar{M}_{\mathrm{w}} / \bar{M}_{\mathrm{n}}\right)$ were determined by SEC with a calibration curve based on narrow poly(methyl methacrylate) (PMMA) standards (from Polymer Standard Services), using the RI detector. Matrix-Assisted Laser Desorption and Ionization Time-of-Flight (MALDI-TOF). Mass spectra were recorded by matrix-assisted laser desorption and ionization time-of-flight (MALDI -TOF) mass spectrometry (MS) using a Bruker autoflex III smartbeam mass spectrometer, equipped with the laser that produces pulses at $337 \mathrm{~nm}$ using dithranol as a matrix and $\mathrm{Nal}$ as cationizing agent. Spectra were recorded in reflector or in linear mode at an accelerating potential of $20 \mathrm{kV}$. Samples were prepared by dissolving the polymer in THF at a concentration of $2 \mathrm{mg} \cdot \mathrm{mL}^{-1}$. A $10 \mu \mathrm{L}$ aliquot of this solution was mixed with $20 \mu \mathrm{L}$ of matrix solution and $10 \mu \mathrm{L}$ of $\mathrm{Nal}$ solution (both at $20 \mathrm{mg}^{\mathrm{mL}} \mathrm{m}^{-1}$ in THF). Standards (poly(ethylene oxide) of known structures, $\bar{M}_{\mathrm{n}}=1120,3500$ and $5500 \mathrm{~g} \cdot \mathrm{mol}^{-1}$ purchased from Polymer Standards Service) were used to calibrate the mass scale. In all cases, to determine $\mathrm{m} / \mathrm{z}$, the molar mass of the sodium cation was added.

\section{Polymerization of 1,2-epoxybutane with carbamate-phosphazene base as initiating system}

The polymerizations were carried out according to the following typical procedure. In a glove-box, $2.0 \mathrm{~mL}$ toluene, $1.06 \mathrm{~mL}$ 1,2-epoxybutane (12.19 mmol), $\mathrm{N}$-methylurethane $(25 \mu \mathrm{L}, 0.245 \mathrm{mmol})$ were introduced under argon into a polymerization tube fitted with a Rotaflo ${ }^{\circ}$. Then, $310 \mu \mathrm{L}$ of $t \mathrm{BuP}_{4}$ solution $(0.248 \mathrm{mmol})$ was added using a microsyringe. After closure of the reaction flask, the reaction mixture was stirred at room temperature and left to react for the required period of time. A small portion of the reaction mixture was sampled through a septum at various reaction times for NMR analyses. The reaction was quenched by addition with $0.1 \mathrm{~mL}$ of 17.1 mol. $\mathrm{L}^{-1}$ acetic acid $(1.71 \mathrm{mmol})$. The polymer was dissolved in THF and purified by passing through neutralized aluminum oxide, filtering and removing the solvent under vacuum at $50{ }^{\circ} \mathrm{C}$ to give a colorless viscous liquid. Yield: $90 \%$. Deviations from this general procedure are summarized in Table 1.

${ }^{1} \mathrm{H}$ NMR $\left(\mathrm{CDCl}_{3}\right)$ : 3.86-3.03 (m, $308 \mathrm{H},-\mathrm{CH}_{2} \mathrm{CHO}$ - polymer backbone, $\left.\mathrm{CH}_{3}-\mathrm{CH}_{2} \mathrm{O}-\right)$, 1.70-1.35 (m, $\left.204 \mathrm{H},-\mathrm{CH}_{2} \mathrm{CH}_{3}\right), 1.17$ (t, $\left.10 \mathrm{H}, \mathrm{CH}_{3}-\mathrm{CH}_{2} \mathrm{O}-\right), 0.907\left(\mathrm{~m}, 300 \mathrm{H},-\mathrm{CH}_{2} \mathrm{CH}_{3}\right)$.

${ }^{13} \mathrm{C} \mathrm{NMR}\left(\mathrm{CDCl}_{3}\right)$ : 80.99-80.56 (- $\left.\mathrm{CH}_{2} \mathrm{CHO}-\right), 72.51-71.53$ ($\left.\mathrm{CH}_{2} \mathrm{CHO}-\right), 66.80\left(\mathrm{CH}_{3} \mathrm{CH}_{2} \mathrm{O}-\right), 25.03-24.83\left(-\mathrm{CH}_{2} \mathrm{CH}_{3}\right), 15.32$ $\left(\mathrm{CH}_{3} \mathrm{CH}_{2} \mathrm{O}-\right)$, 10.05-9.81 (- $\left.\mathrm{CH}_{2} \mathrm{CH}_{3}\right)$. 
Polymerization of 1,2-epoxybutane with carbamate-phosphazene base as initiating system in the presence of triisobutylaluminum (TIBA)

The polymerization was carried out according to the following typical procedure. In a glove-box, $2.0 \mathrm{~mL}$ toluene, $1.06 \mathrm{~mL} \mathrm{1,2-}$ epoxybutane (12.19 mmol), $N$-methylurethane $(25 \mu \mathrm{L}$, $0.245 \mathrm{mmol}$ ) and $670 \mu \mathrm{L}$ triisobutylaluminum solution (0.735 mmol) were introduced under argon into a polymerization tube fitted with a Rotaflo ${ }^{\circ}$. The reaction mixture was stirred at room temperature for $10 \mathrm{~min}$. Then, $310 \mu \mathrm{L}$ of $t \mathrm{BuP}_{4}$ solution $(0.248 \mathrm{mmol})$ was added using a microsyringe. After closure of the reaction flask, the reaction mixture was stirred at room temperature and left to react for the required period of time. Quenching, purification and work-up are similar to polymerization performed without TIBA. Yield: $90 \%$. Deviations from this general procedure are summarized in Table 2.

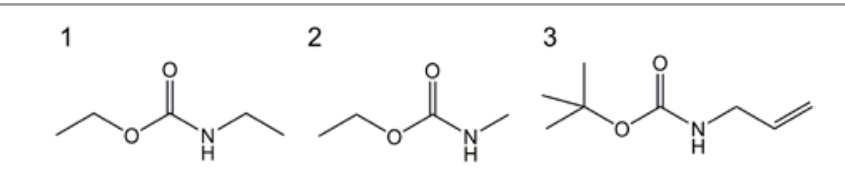

Figure 1. Carbamate-containing molecules used as initiator for the ring-opening polymerization of 1,2epoxybutane.

\section{Results and discussion}

All the polymerization experiments in table 1 were performed in toluene at $25{ }^{\circ} \mathrm{C}$, using 1 equiv of the phosphazene base with respect to the secondary urethane initiator $\mathrm{R}_{1} \mathrm{NHCOOR}_{2}$. Targeted degrees of polymerization, as calculated from the $[\mathrm{M}]_{0} /[\mathrm{XH}]_{0}$ ratio (ie. assuming quantitative initiation), were deliberately set at moderate value so that chain ends could be easily characterized by NMR and MALDI-ToF mass spectrometry. The progress of the reaction was monitored by removing samples from the polymerization reactor and by comparing the signals corresponding to the $-\mathrm{CH}_{2} \mathrm{CH}_{3}$ of both monomer and polymer to the $\mathrm{CH}$ group signal of the oxirane
Scheme 1. Mechanism for the ROP of 1,2-epoxybutane using secondary urethane-phosphazene base as initiating system: (A) expected pathway and (B) postulated mechanism according to experimental results.

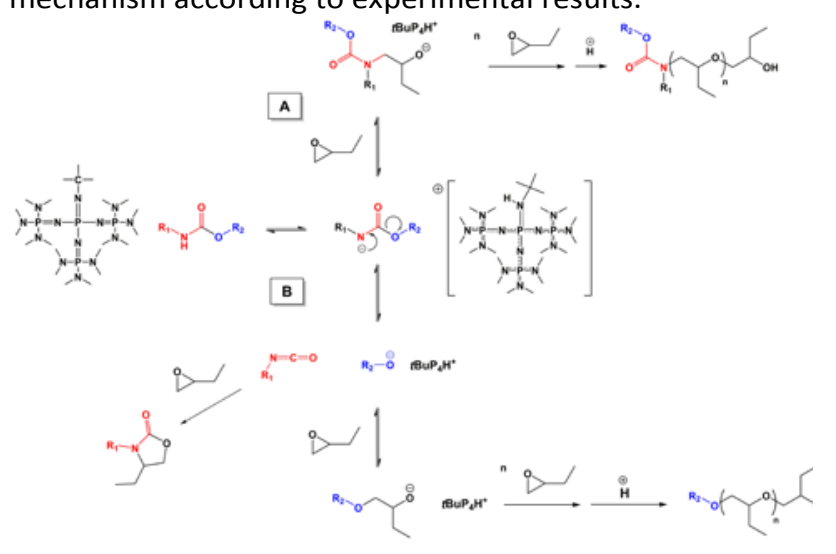

ring. Reactions were ultimately quenched by adding acetic acid. All the polymers were fully characterized by NMR, MALDI-ToF mass spectrometry and SEC chromatography using PMMA standards.

Three experiments (Table 1, run 1-3) were performed using $N$ ethylurethane (Figure 1.1) / $\mathrm{tBuP}_{4}$ as initiating system with $\left[\mathrm{C}_{2} \mathrm{H}_{5} \mathrm{OCONHC}_{2} \mathrm{H}_{5}\right] /\left[\right.$ tBuP $\left._{4}\right]=1 / 1$. 1,2-epoxybutane was successfully polymerized and high conversion were observed. By analogy with polymerization initiated by secondary amide groups, ${ }^{19}$ one can postulate that $t \mathrm{BuP}_{4}$ acts as a deprotonating agent and activates the carbamate for the nucleophilic attack on the ring of 1,2-epoxybutane (Scheme 1.A.). Consequently, the $\alpha$-end groups of the resulting polymers should consist of the carbamate group. MALDI-ToF spectrum (Figure 2) is inconsistent with this assumption and displays a unique peak distribution corresponding to macromolecules cationized by a sodium ion and end-terminated by a hydroxyl group on one end and an alkoxide resulting from the carbamate dissociation according to the mechanism shown in Scheme 1.B on the other end. No polymer chains with an unsaturated end-group resulting from transfer reaction to 1,2-epoxybutane have been detected by mass or NMR spectroscopy. It has to be noted that

Table 1. Experimental conditions and molecular characteristics of polyBO samples synthesized using carbamate-tBuP 4 as initiating system and $[\mathrm{M}]_{0}=3.61 \mathrm{~mol} . \mathrm{L}^{-1}$ in toluene at $25^{\circ} \mathrm{C}$.

\begin{tabular}{|c|c|c|c|c|c|c|c|c|c|}
\hline \multirow[b]{2}{*}{ Run } & \multirow[b]{2}{*}{ Initiator } & \multirow[b]{2}{*}{ Base } & \multirow[b]{2}{*}[\mathrm{M}]{$_{0}-[\text { initiator }]_{0}-[$ Base $]$} & \multirow[b]{2}{*}{ Time (h) } & \multirow[b]{2}{*}{$\mathrm{Cv}^{\mathrm{a}}(\%)$} & \multirow[b]{2}{*}{$\mathbf{M}_{\mathrm{n}, \mathrm{th}}\left(\mathrm{g} \cdot \mathrm{mol}^{-1}\right)$} & \multicolumn{2}{|l|}{ SEC $^{\mathbf{b}}$} & \multirow{2}{*}{$\begin{array}{c}{ }^{1} \mathrm{H} \text { NMR } \\
\mathbf{M}_{\mathrm{n}}\left(\mathrm{g} \cdot \mathrm{mol}^{-1}\right) \\
\end{array}$} \\
\hline & & & & & & & $\mathbf{M}_{\mathrm{n}}\left(\mathrm{g} \cdot \mathrm{mol}^{-1}\right)$ & Ð & \\
\hline 1 & 1 & P4 & $25-1-1$ & 29 & 99 & 1900 & 2300 & 1.15 & 2250 \\
\hline 2 & 1 & P4 & $35-1-1$ & 21.5 & 98 & 2600 & 2900 & 1.09 & 2200 \\
\hline 3 & 1 & P4 & $100-1-1$ & 28.5 & 84 & 6150 & 5800 & 1.08 & - \\
\hline 4 & 2 & P4 & $50-1-1$ & 20 & 80 & 3000 & 5000 & 1,08 & 3550 \\
\hline 5 & 3 & P4 & $50-1-1$ & 27 & 89 & 3400 & 5050 & 1.08 & 3600 \\
\hline 6 & 2 & P2 & 25-1-1 & 24 & 0 & - & - & - & - \\
\hline
\end{tabular}

a Determined by ${ }^{1} \mathrm{H} \mathrm{NMR}$ in $\mathrm{CDCl}_{3} .{ }^{b} \mathrm{THF}, 40^{\circ} \mathrm{C}, \mathrm{PMMA}$ standards. 


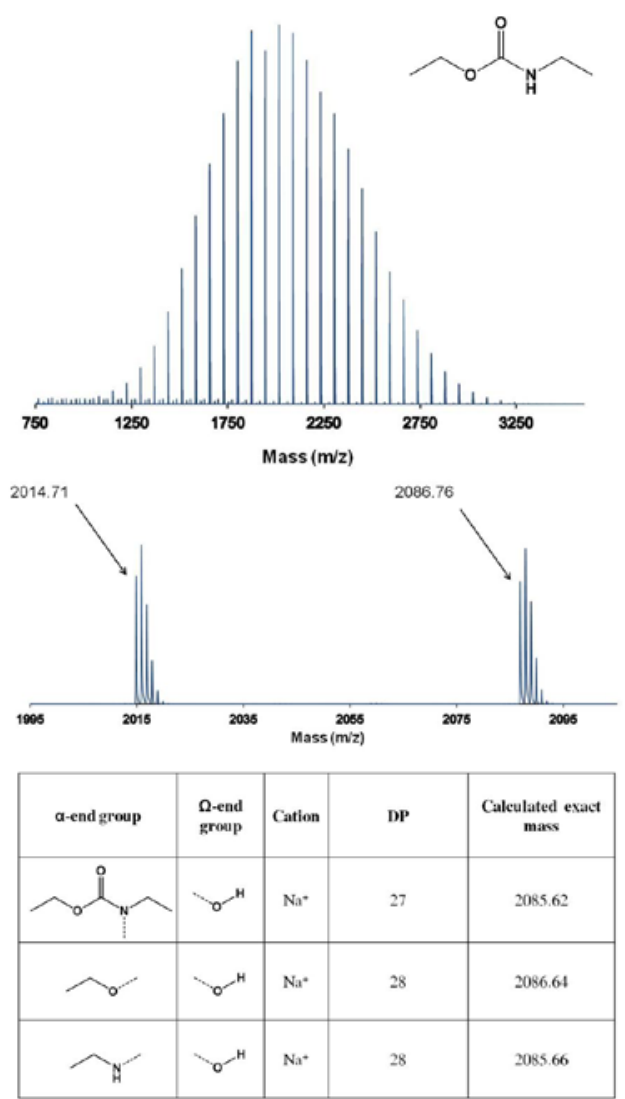

Figure 2. MALDI-ToF spectra (top: linear mode; bottom: reflectron mode) of a poly(butylene oxide) synthesized with $\mathrm{N}$-Methylurethane-tBuP${ }_{4}$ as initiating system (Table 1 , run 1 )

transfer reactions to monomer are not detectable regardless of experimental conditions throughout this study. No carbonyl signals are present on the ${ }^{13} \mathrm{C}$ NMR spectrum which confirms the absence of carbamate chain end (Figure S2). In addition, signals at 15.32 and $66.80 \mathrm{ppm}$ correspond to $\mathrm{CH}_{3}$ and $\mathrm{CH}_{2}$ groups resulting from ethanolate initiation. Under basic conditions, the formation of an amidate anion with a finite lifetime is known. ${ }^{37}, 38$ Numerous examples of secondary carbamates that dissociate in basic media by a two-step elimination mechanism known as E1cB are reported in the literature. ${ }^{37,} 39,40$ After a pre-equilibrium deprotonation step, an alkoxide anion is expelled and an unsaturated isocyanate intermediate is formed (Scheme 1.B.). Isocyanate intermediates have not been observed in the reaction mixture, presumably due to their high reactivity and rapid subsequent reaction with the epoxide monomers to yield an oxazolidinone according to a well-documented reaction. ${ }^{41,42}$ The nucleophilic alkoxide anion initiates the polymerization of 1,2epoxybutane. $\mathrm{CH}_{3}$ at the polymer chain end gives a separate triplet signal at $1.17 \mathrm{ppm}$ on the ${ }^{1} \mathrm{H}$ NMR spectrum (Figure 3.2 ), which allows to calculate molar masses by end group analyses. An excellent agreement is observed between the experimental $\overline{\mathrm{M}} \mathrm{n}$ measured by SEC and ${ }^{1} \mathrm{H}$ NMR and the theoretical ones. In addition, the resulting polymers exhibit narrow molar mass distribution $(\Theta<1.15)$. The later results imply a full and fast carbamate dissociation and a fast subsequent initiation step.

Two other carbamate-containing molecules $(\mathrm{N}$ methylurethane and tert-butyl $\mathrm{N}$-allylcarbamate) were investigated (Figure 1 and Table 1, runs 4-5). As previously, MALDI-ToF spectra show that both polymers have been initiated by alkoxides resulting from carbamate dissociation (see Figures S3 and S5). No backbiting or chain transfer reactions are observed. When tert-butyl $\mathrm{N}$-allylcarbamate was used (Table 1, run 5), a signal corresponding to the tert-butyl group is clearly visible at $1.18 \mathrm{ppm}$ in ${ }^{1} \mathrm{H}$ NMR spectrum (Figure S4) while no signal can be attributed to allyl groups. Both polymers exhibit controlled molar masses and low dispersities. In an attempt to avoid the carbamate dissociation, a weaker

Table 2. Experimental conditions and molecular characteristics of polyBO samples synthesized with $N$-methylurethane-tBuP 4 initiating systems in the presence of triisobutylaluminum.

\begin{tabular}{|c|c|c|c|c|c|c|c|c|c|c|c|}
\hline \multirow[b]{2}{*}{ Run } & \multirow[b]{2}{*}[\mathrm{M}]{$_{0}-[\text { Initiator }]_{0}-[\text { Base }]_{0}-[\mathrm{Al}]$} & \multirow[b]{2}{*}{ Solvent } & \multirow[b]{2}{*}{ Base } & \multirow[b]{2}{*}[\mathrm{M}]{$_{0}$} & \multirow[b]{2}{*}{$\mathrm{T}^{\circ}$} & \multirow[b]{2}{*}{ Time (h) } & \multirow[b]{2}{*}{$\operatorname{Cv}(\%)^{\mathrm{a}}$} & \multirow[b]{2}{*}{$\mathrm{M}_{\mathrm{n}, \text { th }}\left(\mathrm{g} \cdot \mathrm{mol}^{-1}\right)$} & \multicolumn{2}{|l|}{ SEC } & \multirow{2}{*}{$\begin{array}{c}{ }^{1} \mathrm{H}-\mathrm{NMR} \\
\mathrm{M}_{\mathrm{n}}\left(\mathrm{g} \cdot \mathrm{mol}^{-1}\right)^{\mathrm{c}}\end{array}$} \\
\hline & & & & & & & & & $\mathrm{M}_{\mathrm{n}}\left(\mathrm{g} \cdot \mathrm{mol}^{-1}\right)^{\mathrm{b}}$ & 甲 & \\
\hline 1 & $50-1-1-3$ & Toluene & P4 & 3.1 & 25 & 22 & 100 & 3700 & 4800 & 2.50 & - \\
\hline 2 & $50-1-1-1$ & Toluene & P4 & 3.2 & 25 & 0.33 & 100 & 3700 & 4250 & 1.24 & - \\
\hline 3 & $50-1-1-1$ & Toluene & P2 & 3.1 & 25 & 20 & 100 & 3700 & 3600 & 1.20 & 3500 \\
\hline 4 & $50-1-1-3$ & MeTHF & P4 & 3.1 & 25 & 3.5 & 95 & 3550 & 3600 & 1.83 & - \\
\hline 5 & $50-1-1-3$ & MeTHF & P4 & 3.1 & 25 & 3 & 100 & 3700 & 4600 & 1.30 & - \\
\hline 6 & $50-1-1-3$ & MeTHF & P4 & 0.6 & 25 & 22 & 50 & 1900 & 1600 & 2.00 & - \\
\hline 7 & $50-1-1-3$ & MeTHF & P4 & 3.1 & 0 & 3 & 100 & 3700 & 7700 & 1.74 & - \\
\hline 8 & $50-1-1-3$ & MeTHF & P4 & 3.1 & 50 & 3 & 100 & 3700 & 2000 & 2.10 & - \\
\hline 9 & $50-1-1-3$ & MeTHF & P2 & 3.1 & 25 & 3 & 100 & 3700 & 3400 & 2.60 & - \\
\hline 10 & $50-1-1-1$ & MeTHF & P4 & 3.1 & 25 & 24 & 100 & 3700 & 4800 & 1.40 & - \\
\hline 11 & $50-1-1-1$ & MeTHF & P4 & 3.1 & 25 & 23 & 100 & 3700 & 4000 & 1.28 & - \\
\hline 12 & $50-1-1-1$ & MeTHF & P2 & 3.1 & 25 & $20(8)^{d}$ & $100(52)^{d}$ & 3700 & 4200 & 1.30 & 4150 \\
\hline
\end{tabular}

${ }^{a}$ Determined by ${ }^{1} \mathrm{H} \mathrm{NMR}$ in $\mathrm{CDCl}_{3} .{ }^{b}$ Determined by SEC (THF, $40^{\circ} \mathrm{C}$, PMMA standards). ${ }^{c}$ Determined by ${ }^{1} \mathrm{H} \mathrm{NMR}$ in CDCl 3 .Only possible in the absence of transfer reaction. ${ }^{d}$ The values in parentheses correspond to an aliquot after $8 \mathrm{~h}$ reaction. 


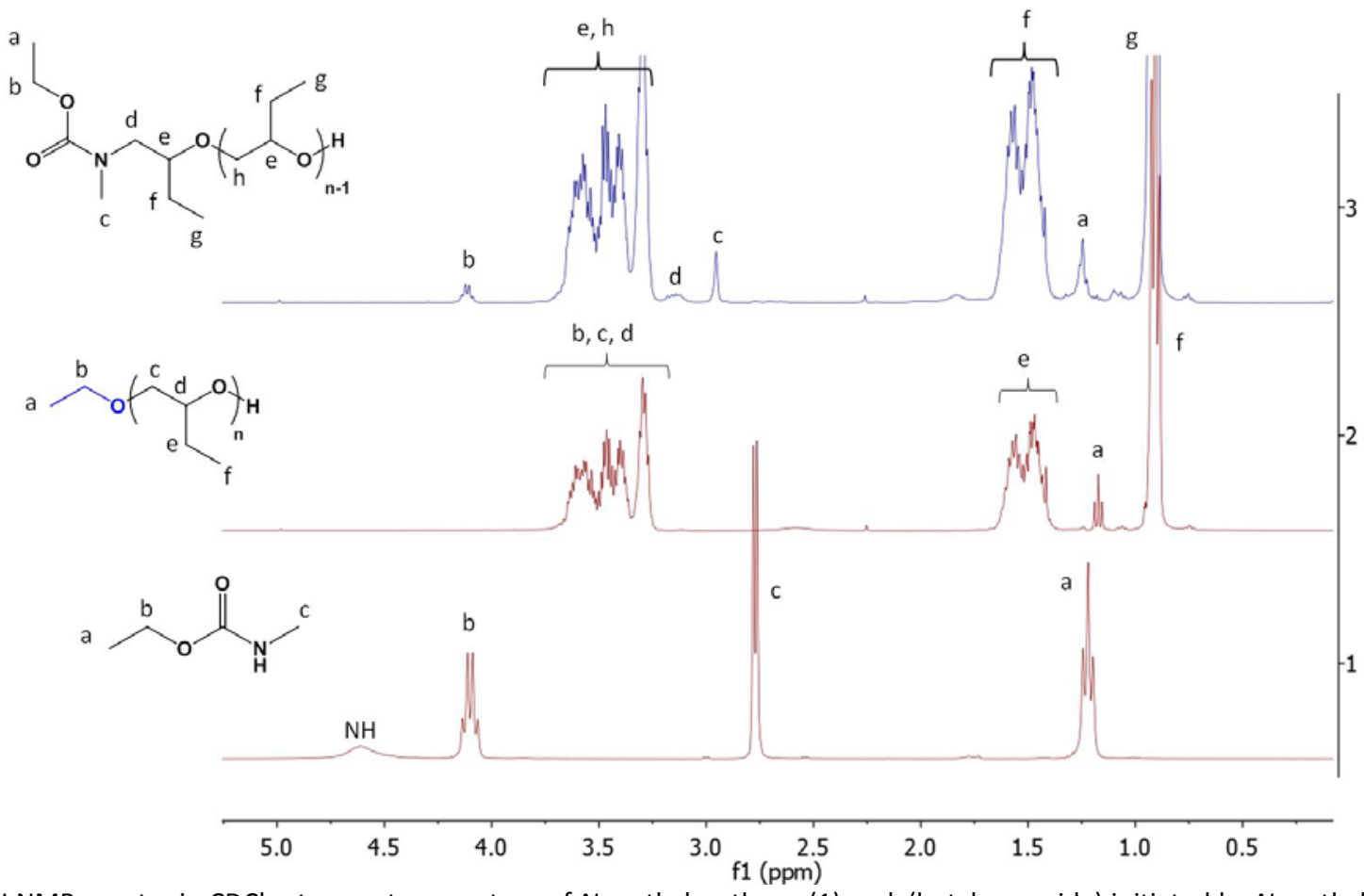

Figure 3. ${ }^{1} \mathrm{H}$ NMR spectra in $\mathrm{CDCl}_{3}$ at room temperature of $\mathrm{N}$-methylurethane (1), poly(butylene oxide) initiated by $N$-methylurethane in the absence (2, Table 1 run 4$)$ or in the presence $(3$, Table 2 run 2 ) of triisobutylaluminum.

phosphazene base $-t \mathrm{BuP}_{2}-\left(\mathrm{pK}_{\mathrm{a}, \mathrm{ACN}}=33.5 \mathrm{vs} \mathrm{pK}_{\mathrm{a}, \mathrm{ACN}}=42.7\right)$ has been used in combination with $N$-ethylurethane (Table 1 , run 6) but no polymerization occurred.

Eventually, controlled polymerizations are obtained with carbamate-tBuP 4 as initiating systems but latter systems did not permit the grafting of a polymer chain on the carbamate nitrogen atom. The nature of polymer alpha end-group is nevertheless controlled by selecting the carbamate ester part. The next reaction was carried out with 3 equivalents of a Lewis acid: triisobutylaluminum (Table 2, run 1). Lewis acids can interact with a lone pair of electrons on the carbonyl oxygen and this complexation is known to have a dramatic effect on the reactivity of carbonyl compounds. ${ }^{43}$ Carbonyl-Lewis acid coordination plays a fundamental role in organic and bioorganic chemistry. In our case, the addition of a Lewis acid was expected to stabilized the carbamate anion generated by the $\mathrm{NH}$ deprotonation. The carbamate electron density should be decreased and thus, the alkoxide elimination should be avoided. $N$-methylurethane, 1,2-epoxubutane, toluene and triisobutyl aluminum were first added in the polymerization reactor and were stirred at room temperature. After 10 minutes, phosphazene base was added to the solution. The polymerization was quenched after 22 hours reaction at $25^{\circ} \mathrm{C}$. The MALDI-ToF analysis of the resulting polymer (Figure S9 and Figure 4) shows two major and one minor distributions. They all correspond to polymers cationized by $\mathrm{Na}^{+}$and none of them could match alkoxide initiation. The minor series can be attributed to the expected carbamate and hydroxide end groups. These results demonstrate that the aluminum derivative fulfilled its intended purpose by preventing the carbamate anions decomposition. The latter are nucleophilic enough to initiate the anionic ring-opening polymerization of 1,2-epoxybutane. One of the two major peak series can be attributed to PBO chains with methyl and hydroxide end groups (Figure 4, distribution C) which indicates the occurrence of a transfer reaction to the aluminum derivative resulting in hydride initiation according to a mechanism shown in Supporting Information (Figure S7.A). ${ }^{44}$ The second major distribution results from acid desactivation and isobutyl group initiation (Figure 4, distribution $D$ ) resulting from another type of transfer reaction to $\mathrm{BBu}_{3} \mathrm{Al}$ (Figure S7.B). In the reaction mixture, aluminum derivative is in 3 -fold excess with respect to carbamate. Thus, we can assume the existence of two plausible complexation sites in addition to the carbonylaluminum derivative complex (Figure S6). On the one hand, aluminium alkyl is coordinated to the alcoholate of the living structure resulting in a poly(butylenoxy)triisobutyl aluminate phosphazenium growing chains of presume 1:1:1 stoichiometry. ${ }^{4}$ Taking in account that completion of the polymerization is reached in less than $20 \mathrm{~min}$, it is suggested a monomer activation through oxygen coordination onto the electrophilic aluminum center according to an activated monomer mechanism. ${ }^{45}$ 


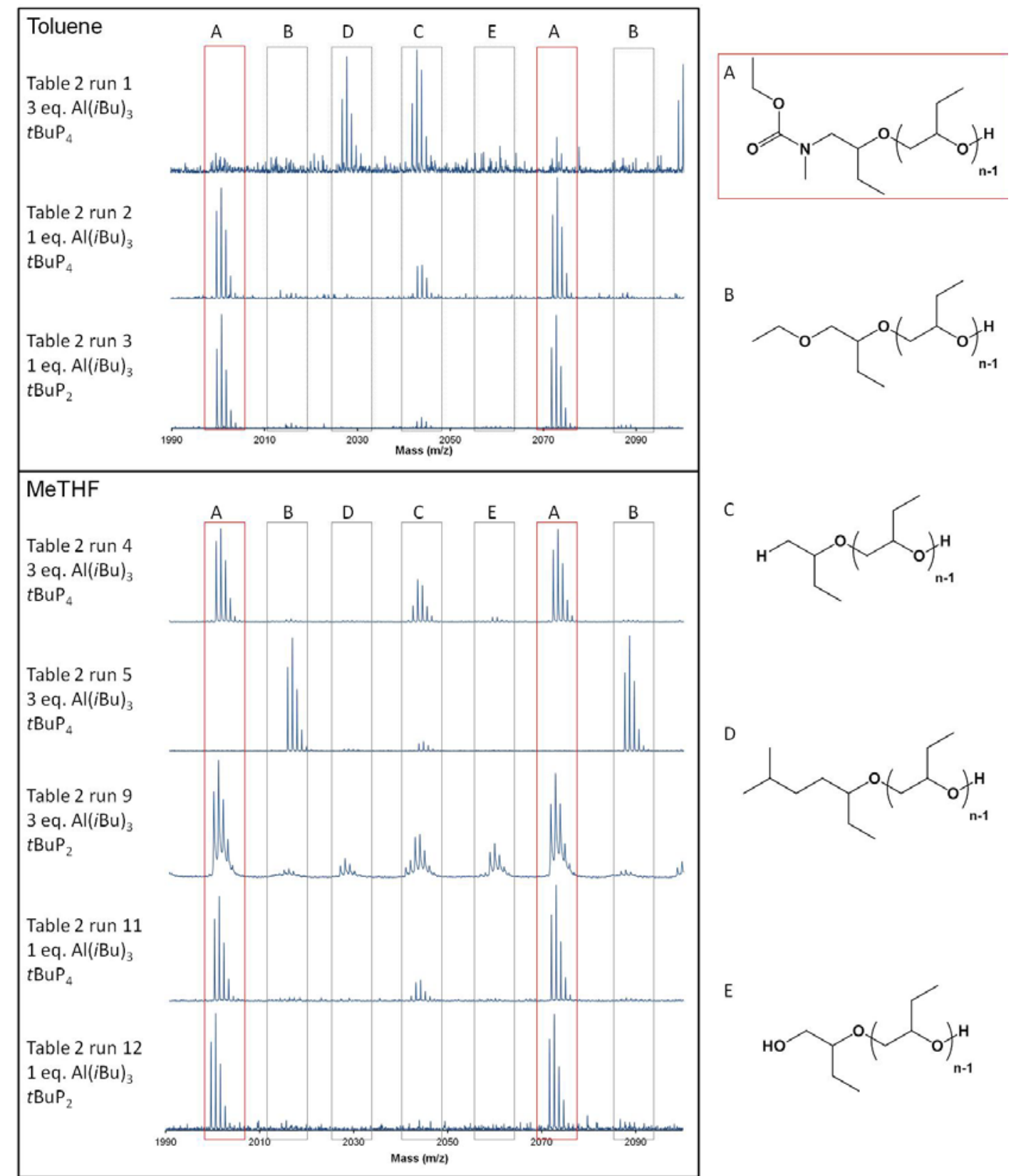

Figure 4. MALDI-ToF spectra (reflectron mode) of a poly(butylene oxide)s synthesized with $N$-Methylurethane-tBuP ${ }_{4}$ as initiating system under different reaction conditions.

In order to limit transfer reaction to $i \mathrm{Bu}_{3} \mathrm{Al}$, an experiment (Table 2 run 2) was carried out with [carbamate]/[iBu$\left.u_{3} \mathrm{Al}\right] /\left[t \mathrm{BuP}_{4}\right]$ molar ratio equal to $1 / 1 / 1$ (i.e. decrease of Al). The MALDI ToF spectrum (Figure 4 ) shows that a large majority of the polymer chains have the expected structure, i.e., polyBO end-terminated with $\mathrm{N}$-methylurethane on one end and hydroxyl group on the other end (Figure 4, structure A). One minor distribution with the same repetition unit, but different chain ends, could be observed in the spectrum. It corresponds to polyBO initiated by hydride anion issued from transfer reaction to TIBA (Figure 4, structure C). Isobutyl initiated polymer chains have not been detected. Overall, the use of stoichiometric ratio between TIBA and carbamate has strongly reduced the occurrence of transfer reactions to aluminum derivative. A kinetic study was carried out: the degree of polymerization increased linearly with conversion over the entire conversion range confirming an almost complete absence of transfer reaction (Figure S11). On the other hand, the monomer conversion remains very low up to 100 minutes suggesting either a latency period or a system with slow initiation rate. Then, the semilogarithmic kinetic curve is linear confirming that the active sites concentration stayed constant (no termination reaction) until the end of the polymerization resulting in a first order kinetics with respect to monomer. A value of $0.0460 \mathrm{~L} . \mathrm{min}^{-1} . \mathrm{mol}^{-1}$ for the propagation rate constant, $k_{p, a p p}$, was calculated from the slope of the regression line (Figure S11). This value is of the same order of magnitude than the one previously obtained for the 
polymerization of $\mathrm{BO}$ in presence of $t \mathrm{BuP}_{4}(\mathrm{kp}, \mathrm{app}=0.0336$ L. $\left.\mathrm{min}^{-1} \cdot \mathrm{mol}^{-1}\right) \cdot{ }^{19}$ When reactions are performed with [Initiator $]_{0}-[\mathrm{P}]_{0}-[\mathrm{Al}]=1-1-1$, the aluminum derivative stabilizes the carbamate groups but did not interact with kinetics results according to the mechanism represented in Scheme 2 .

To further reduce transfer reactions, $t \mathrm{BuP}_{4}$ has been replaced by $t_{B u P_{2}}$ (run 3, Table 2). The radius of the phosphazenium cation tBuP ${ }_{2} \mathrm{H}^{+}$is smaller $(r=3.3 \AA)$ than the one of $t \mathrm{BuP}_{4} \mathrm{H}^{+}(\sim 5 \AA) .{ }^{46}$ Moreover, the positive charge is delocalized over 9 positions in $t \mathrm{BuP}_{2}$ compared with 17 positions in $t \mathrm{BuP}_{4}$. Thus, one can reasonably assume that the interionic distances between the propagating centers and the phosphazenium cations will be reduced in the case of the $t \mathrm{BuP}_{2}$ base, which should result in a decrease of the propagating center reactivity. In run 3, Table 2, an increase of selectivity toward the ring-opening polymerization to the detriment of the aluminum derivative transfer reaction was observed. Transfer reactions have almost disappeared and a large majority of the chains have the expected structure (Figure 4). The ${ }^{1} \mathrm{H}$ NMR spectrum displays all the characteristic signals of polyBO and $\mathrm{N}$-methylurethane (Figure 3.3). After polymer purification, the triplet and quadruplet associated with the carbamate $\mathrm{CH}_{3} \mathrm{CH}_{2}$ group are still observed at 1.25 and $4.11 \mathrm{ppm}$. This assignment is confirmed by a COSY NMR spectrum (Figure S14) and HSQC NMR experiment (Figure S15) that indicated correlations between the $\mathrm{CH}_{3} \mathrm{CH}_{2}$ - proton signals and peaks at 14.85 and $61.27 \mathrm{ppm}$ on the ${ }^{13} \mathrm{C}$ NMR spectrum compatible with the $\mathrm{CH}_{3} \mathrm{CH}_{2} \mathrm{O}$ - group of a carbamate. Further evidence regarding the presence of the carbamate initiator was obtained from the signal of the $N$-methyl protons at $2.95 \mathrm{ppm}$. The chemical shift of the $\mathrm{N}$-methyl proton is slightly different from the one of the parent carbamate and collapse to sharp singlet (Figure 3). COSY and HSQC NMR spectra are ultimately in perfect agreement with the expected structure. The number-average molar masse of polyBO (run 3, Table 2), which was estimated by ${ }^{1} \mathrm{H}$ NMR analysis, is in good agreement with the one calculated from the initial ratio $[\mathrm{BO}]_{0} /[1]_{0}$ and the monomer conversion. Under these conditions, a good polymerization control is achieved and the dispersity is reduced to 1.20. Zhao et al. have shown the feasibility of ethylene oxide polymerization catalyzed by tBuP $2 .{ }^{47}$ Interestingly in our case, no polymerization was previously noticed when using $t \mathrm{BuP}_{2}$ as deprotonating agent (Table 1, run 6)

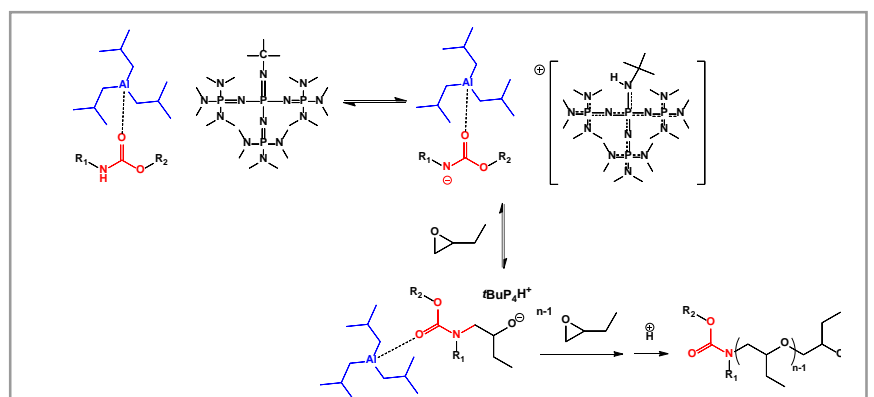

Scheme 2. Postulated mechanism for the ROP of 1,2epoxybutane using secondary urethanetriissobutylaluminum-phosphazene base (1-1-1) as initiating system. while polymerization took place in the presence of TIBA (Table 2) This is probably due to the enhanced acidity of the hydrogen on the carbamate nitrogen. The coordination of a Lewis acid to a Brønsted acid can in fact significantly increase its original acidity. ${ }^{48}$ For example, coordination of a ketone or an aldehyde by Lewis acid enhanced the acidity of the $\alpha$-hydrogen in the complex. ${ }^{49}$

In order to increase the reactivity of the carbamate anion, experiments were carried out in a slightly more polar solvent: $\operatorname{MeTHF}\left(\varepsilon_{\text {MeTHF }}=6.29 ; \varepsilon_{\text {Toluene }}=2.38\right)$. MeTHF was used rather than THF $(\varepsilon=7.58)$ because Carlotti and coll. ${ }^{50}$ have demonstrated that THF have a tendency to complexation with trialkyl aluminum. The steric hindrance introduced by the methyl group on the MeTHF prevents this complexation and makes TIBA more available to play its carbamate anion protective role. Moreover, MeTHF is a biomassderived chemical which is currently considered as a promising environmentally friendly alternative to petro-based solvents. In the presence of 3 eq. of aluminum derivative (Tables 2, run 4), the main distribution corresponds to the expected structure, i.e. an initiation by the nitrogen atom of the carbamate. Compared to reactions in toluene in the same conditions, transfer reactions to triisobutylaluminum have been reduced: chains initiated by isobutyl anion are not observed and hydride initiated chains are in minority (Figure 4). Both alpha end-groups (carbamate and $\mathrm{CH}_{3}$ ) are visible in the ${ }^{1} \mathrm{H}$ NMR spectrum (Figure S16). It is noteworthy that if the reagent addition order is reversed and $t \mathrm{BuP}_{4}$ is added just before triisobutylaluminum (Table 2, run 5), there is no carbamate initiation and only alkoxide-initiated chains are observed which implies an extremely fast carbamate decomposition in the presence of phosphazene base. The influence of the reaction temperature has been studied and experiments were performed at $0^{\circ} \mathrm{C}$ (Table 2 , run 7 ) and $50^{\circ} \mathrm{C}$ (Table 2, run 8 ) without improving previous results (Figure S20 and S21). Monomer concentration was divided by 5 (Table 2, run 6) and also in this case, no improvement was noticed (Figure S18). The replacement of $t \mathrm{BuP}_{4}$ by $t \mathrm{BuP}_{2}$ (Table 2, run 9) has no positive effect: on the contrary, the dispersity and the number of distributions in MALDI-ToF increased (Figures S22 and S23). As in the case of toluene, in MeTHF, the use of a stoichiometric ratio between carbamate, TIBA and $t \mathrm{BuP}_{4}$ (Table 2, run 11), strongly decreased the amount of transfer reactions (Figure 4) and the dispersity of the resulting polymer. A kinetic study was carried out and is shown in Figure S26 in Supporting Information. Propagation rate constant $k_{p}$ was extracted from the slope of the regression line. The $k_{p}$ value of $0.0492 \mathrm{~L} . \mathrm{min}^{-1} \cdot \mathrm{mol}^{-1}$ can be directly compared to the $0.0460 \mathrm{~L} . \mathrm{min}^{-1} \cdot \mathrm{mol}^{-1}$ value obtained in toluene at the same temperature for the same concentrations. These practically identical values obtained whatever the solvent used are surprising as MeTHF is more polar and therefore more dissociative solvent than toluene. Nevertheless, this result is consistent with the previously published rate constants of the polymerization of cyclopropane-1,1-dicarboxylates with phosphazenium counter-ion in THF and toluene. ${ }^{12}$ Eventually, using a stoichiometric ratio for the initiating system and $t \mathrm{BuP}_{2}$ as superbase, the expected carbamateinitiated polymer chains were the only population detected in MALDI-ToF spectrum (Figure 4). Further evidence regarding the presence of the initiator was obtained from ${ }^{13} \mathrm{C}$ NMR spectroscopy (Figure S28). The signals associated to the carbamate end-group are 
observed at $156.8 \mathrm{ppm}(\mathrm{C}=\mathrm{O}), 61.3 \mathrm{ppm}\left(\mathrm{CH}_{3} \mathrm{CH}_{2}-\right), 36.3 \mathrm{ppm}\left(\mathrm{CH}_{3}-\right.$ $\mathrm{N})$ and $14.8 \mathrm{ppm}\left(\mathrm{CH}_{3} \mathrm{CH}_{2}-\right)$. A number-average molar mass of 4150 g. mol ${ }^{-1}$ was precisely determined by ${ }^{1} \mathrm{H}$ NMR spectroscopy by virtue of the absence of transfer reaction. This value is in good agreement with the value determined by size exclusion chromatography and the theoretical value. Molecular weight distribution is quite narrow but the 1.3 dispersity value and the shape of the distribution (tail) strongly suggest a rather slow initiation step.

\section{Conclusions}

In conclusion, we have demonstrated that the catalytic system obtained from the combination of carbamate-containing molecules-aluminum derivative-phosphazene base at ratio 11-1 is an efficient initiator for the controlled polymerization of 1,2-epoxybutane. The addition of triisobutylaluminum was necessary to stabilize carbamate anions. The relative amount of introduced Lewis acid has a strong influence on the occurrence of transfer reactions. These new class of initiator is expected to produce new synthetic strategies for chain-end functionalization such as the grafting of a polymer chain on carbamate-containing prodrugs or for the synthesis of complex macromolecules such as graft-polymers from polyurethanes with applications in material sciences.

\section{Acknowledgements}

This work was supported by the LabEx MiChem part of French state funds managed by the ANR within the Investissements d'Avenir programme under reference ANR-11-IDEX-0004-02.

\section{Notes and references}

1. S. Boileau and N. Illy, Progress in Polymer Science, 2011, 36, 1132-1151.

2. H. Misaka, R. Sakai, T. Satoh and T. Kakuchi, Macromolecules, 2011, 44, 9099-9107.

3. H. Yang, J. Xu, S. Pispas and G. Zhang, Macromolecules, 2012, 45, 3312-3317.

4. A.-L. Brocas, A. Deffieux, N. Le Malicot and S. Carlotti, Polymer Chemistry, 2012, 3, 1189-1195.

5. H. Misaka, E. Tamura, K. Makiguchi, K. Kamoshida, R. Sakai, T. Satoh and T. Kakuchi, Journal of Polymer Science Part A: Polymer Chemistry, 2012, 50, 1941-1952.

6. J. Zhao, D. Pahovnik, Y. Gnanou and N. Hadjichristidis, Journal of Polymer Science Part A: Polymer Chemistry, 2015, 53 304-312.

7. J. Zhao, D. Pahovnik, Y. Gnanou and N. Hadjichristidis, Macromolecules, 2014, 47, 3814-3822.

8. J. Zhao, H. Schlaad, S. Weidner and M. Antonietti, Polymer Chemistry, 2012, 3, 1763-1768.

9. H. Schlaad, H. Kukula, J. Rudloff and I. Below, Macromolecules, 2001, 34, 4302-4304.

10. M. Helou, O. Miserque, J.-M. Brusson, J.-F. Carpentier and S. M. Guillaume, Chemistry - A European Journal, 2010, 16, 1380513813.
11. T. Isono, K. Kamoshida, Y. Satoh, T. Takaoka, S.-i. Sato, T. Satoh and T. Kakuchi, Macromolecules, 2013, 46, 3841-3849.

12. N. Illy, S. Boileau, W. Buchmann, J. Penelle and V. Barbier, Macromolecules, 2010, 43, 8782-8789.

13. N. Illy, S. Boileau, J. Penelle and V. Barbier, Macromolecular Rapid Communications, 2009, 30, 1731-1735.

14. N. Illy, D. Majonis, I. Herrera, O. Ornatsky and M. A. Winnik, Biomacromolecules, 2012, 13, 2359-2369.

15. J. De Winter, O. Coulembier, P. Gerbaux and P. Dubois, Macromolecules, 2010, 43, 10291-10296.

16. M. Kawalec, O. Coulembier, P. Gerbaux, M. Sobota, J. De Winter, P. Dubois, M. Kowalczuk and P. Kurcok, Reactive and Functional Polymers, 2012, 72, 509-520.

17. C. Samuel, Y. Chalamet, F. Boisson, J.-C. Majesté, F. Becquart and E. Fleury, Journal of Polymer Science Part A: Polymer Chemistry, 2014, 52, 493-503.

18. J. Zhao and H. Schlaad, Macromolecules, 2011, 44, 58615864.

19. L. Dentzer, C. Bray, S. Noinville, N. Illy and P. Guégan, Macromolecules, 2015, 48, 7755-7764.

20. A. K. Ghosh and M. Brindisi, Journal of Medicinal Chemistry, 2015, 58, 2895-2940.

21. P. G. M. Wuts and T. W. Greene, in Greene's Protective Groups in Organic Synthesis, John Wiley \& Sons, Inc., 2006, DOI: 10.1002/9780470053485.ch7, pp. 696-926.

22. R. N. Salvatore, S. I. Shin, V. L. Flanders and K. W. Jung, Tetrahedron Letters, 2001, 42, 1799-1801.

23. K. Fujita, A. Komatsubara and R. Yamaguchi, Tetrahedron, 2009, 65, 3624-3628.

24. S. Daum, V. F. Chekhun, I. N. Todor, N. Y. Lukianova, Y. V. Shvets, L. Sellner, K. Putzker, J. Lewis, T. Zenz, I. A. M. de Graaf, G. M. M. Groothuis, A. Casini, O. Zozulia, F. Hampel and A. Mokhir, Journal of Medicinal Chemistry, 2015, 58, 2015-2024.

25. P. S. Mukesh, R. R. Ramakrishna, R. Veerbhadra, N. D. Sunil and B. S. Devanand, Letters in Organic Chemistry, 2013, 10, 6064.

26. C. R. Reddy, B. Mahipal and S. R. Yaragorla, Arkivoc, 2008, 250-257.

27. A. J. T. Teo, A. Mishra, I. Park, Y.-J. Kim, W.-T. Park and Y.-J. Yoon, ACS Biomaterials Science \& Engineering, 2016, 2, 454-472.

28. D. M. S. Al-Homoud, Building and Environment, 2005, 40, 353-366.

29. S. Hayashi, N. Ishikawa and C. Giordano, Journal of Coated Fabrics, 1993, 23, 74-83.

30. G. Zhou, C. Ma and G. Zhang, Polymer Chemistry, 2011, 2, 1409-1414.

31. J. G. Archambault and J. L. Brash, Colloids and Surfaces B: Biointerfaces, 2004, 39, 9-16.

32. J. G. Archambault and J. L. Brash, Colloids and Surfaces B: Biointerfaces, 2004, 33, 111-120.

33. Y.-C. Chung, H. Y. Kim, J. W. Choi and B. C. Chun, Polymer Bulletin, 2015, 72, 2685-2703.

34. V. Percec and C. Grigoras, Journal of Polymer Science Part A: Polymer Chemistry, 2005, 43, 5283-5299.

35. D. Giannakidis and H. J. Harwood, Journal of Polymer Science: Polymer Letters Edition, 1978, 16, 491-496. 
36. F. G. Bordwell and H. E. Fried, The Journal of Organic Chemistry, 1991, 56, 4218-4223.

37. M. L. Bender and R. B. Homer, The Journal of Organic Chemistry, 1965, 30, 3975-3978.

38. F. W. Abbate, W. J. Farrissey and A. A. R. Sayigh, Journal of Applied Polymer Science, 1972, 16, 1213-1234.

39. L. W. Dittert and T. Higuchi, Journal of Pharmaceutical Sciences, 1963, 52, 852-857.

40. A. Williams, Journal of the Chemical Society, Perkin Transactions 2, 1973, DOI: 10.1039/p29730001244, 1244-1247.

41. J. S. Senger, I. Yilgor, J. E. McGrath and R. A. Patsiga, Journal of Applied Polymer Science, 1989, 38, 373-382.

42. Q.-W. Lu, T. R. Hoye and C. W. Macosko, Journal of Polymer Science Part A: Polymer Chemistry, 2002, 40, 2310-2328.

43. T. Ooi and K. Maruoka, in Modern Carbonyl Chemistry, WileyVCH Verlag GmbH, 2007, DOI: 10.1002/9783527613267.ch01, pp. 1-32.

44. V. Rejsek, P. Desbois, A. Deffieux and S. Carlotti, Polymer, 2010, 51, 5674-5679.

45. C. Billouard, S. Carlotti, P. Desbois and A. Deffieux, Macromolecules, 2004, 37, 4038-4043.

46. J. G. Hinman, A. J. Lough and R. H. Morris, Inorganic Chemistry, 2007, 46, 4392-4401.

47. J. Zhao, D. Pahovnik, Y. Gnanou and N. Hadjichristidis, Polymer Chemistry, 2014, 5, 3750-3753.

48. W. Shi, J. Zhao, X. Yuan, S. Wang, X. Wang and M. Huo, Chemical Engineering \& Technology, 2012, 35, 347-352.

49. J. Ren, C. J. Cramer and R. R. Squires, Journal of the American Chemical Society, 1999, 121, 2633-2634.

50. K. Roos and S. Carlotti, European Polymer Journal, 2015, 70, 240-246. 


\title{
Supporting Information for
}

\section{Phosphazene/Triisobutylaluminum-Promoted Anionic Ring- Opening Polymerization of 1,2-Epoxybutane Initiated by Secondary Carbamates}

\author{
Lilia Hassouna, Nicolas Illy* and Philippe Guégan
}

Sorbonne Universités, UPMC Univ Paris 6, CNRS, Institut Parisien de Chimie Moléculaire, Equipe Chimie des Polymères, 4 place Jussieu, F-75005 Paris, France. 
a.

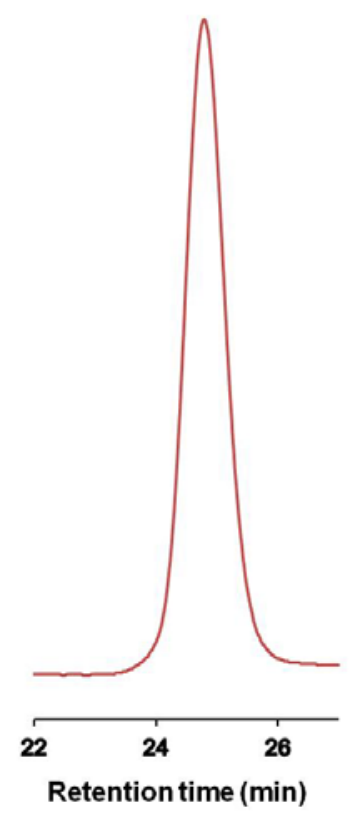

b.<smiles>CCOCC(CC)OC</smiles>

Figure S1. SEC traces (left) and ${ }^{1} \mathrm{H}$ NMR spectrum in $\mathrm{CDCl}_{3}$ (right) of a poly(butylene oxide) synthesized with $N$-ethylurethane-tBuP 4 as initiating system (Table 1, run 1).
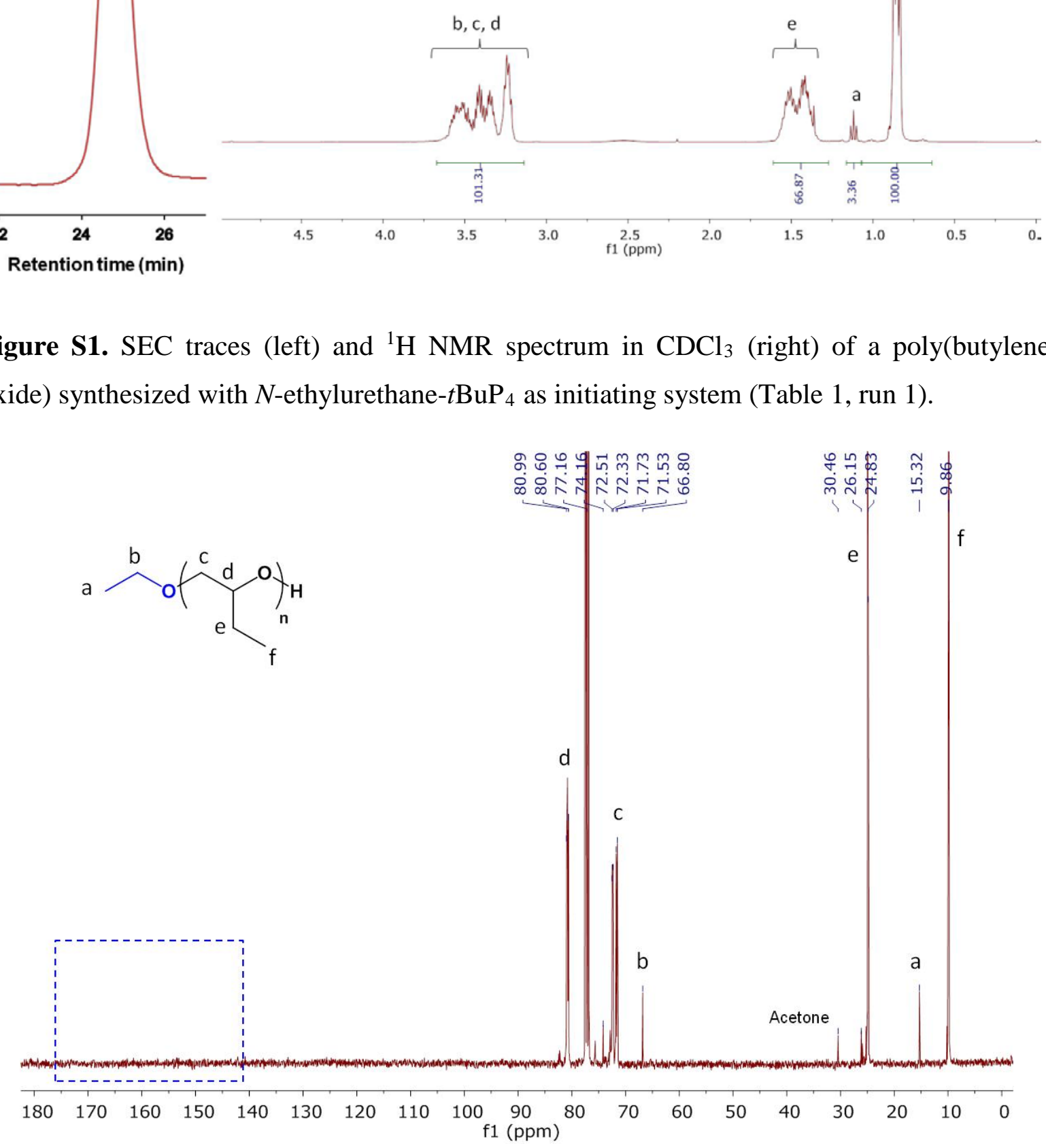

Figure S2. ${ }^{13} \mathrm{C}$ NMR spectrum in $\mathrm{CDCl}_{3}$ of a poly(butylene oxide) synthesized with $\mathrm{N}$ ethylurethane-tBuP 4 as initiating system (Table 1 , run 1 ). 

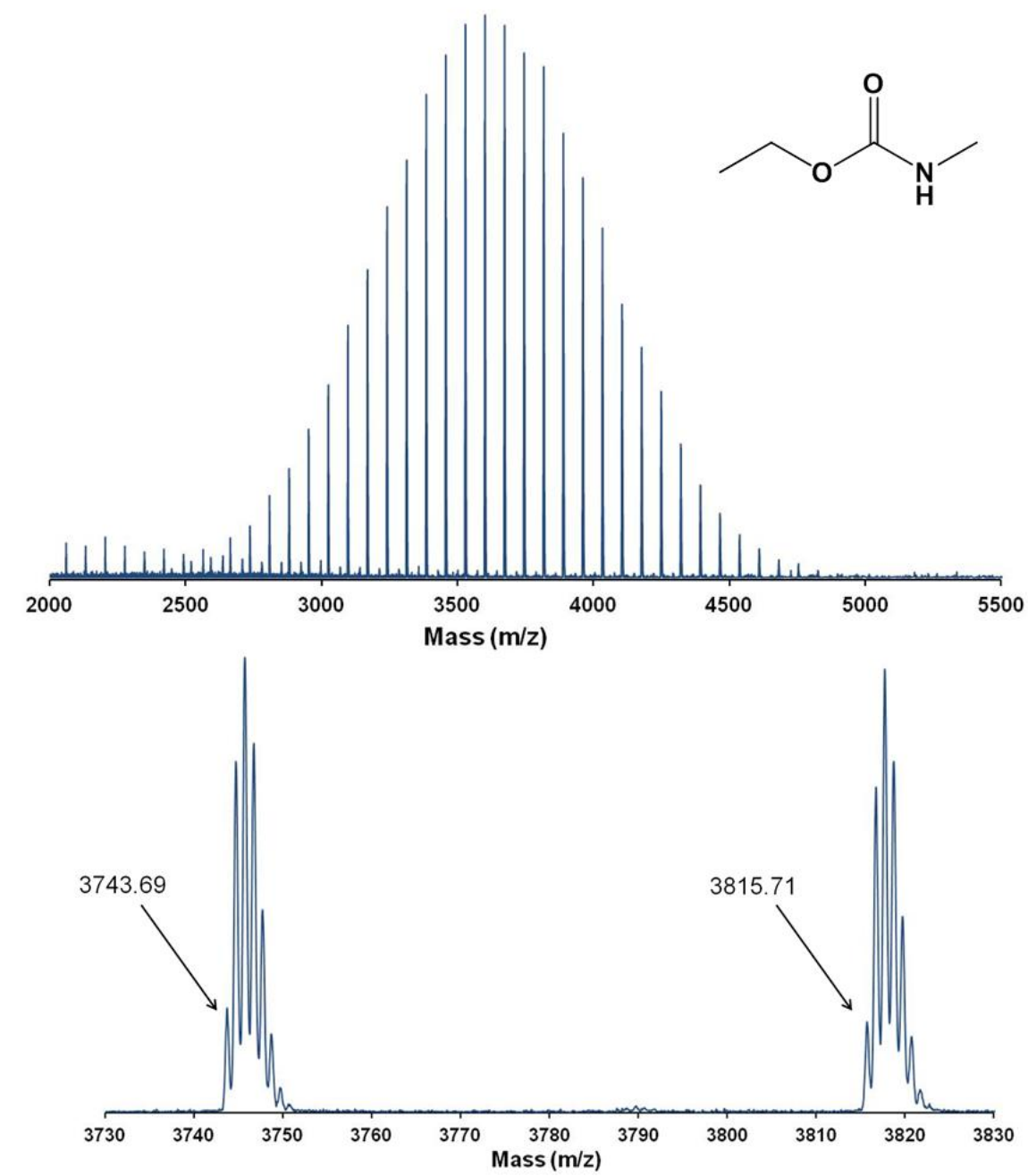

\begin{tabular}{|c|c|c|c|c|}
\hline a-end group & $\begin{array}{l}\Omega \text {-end } \\
\text { group }\end{array}$ & Cation & DP & $\begin{array}{c}\text { Calculated exact } \\
\text { mass }\end{array}$ \\
\hline & & $\mathrm{Na}^{+}$ & 51 & 3800.99 \\
\hline & & $\mathrm{Na}^{+}$ & 52 & 3816.02 \\
\hline & & $\mathrm{Na}^{+}$ & 52 & 3801.02 \\
\hline
\end{tabular}

Figure S3. MALDI-ToF spectra (top: linear mode; bottom: reflectron mode) of a poly(butylene oxide) synthesized with $N$-Methylurethane-tBuP 4 as initiating system (Table 1 , run 4). 
a.

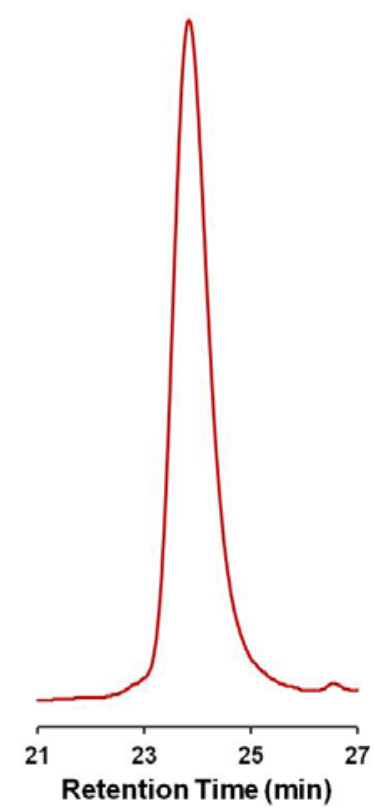

b.

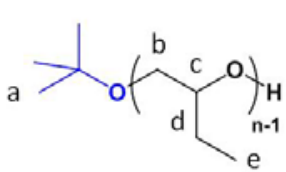

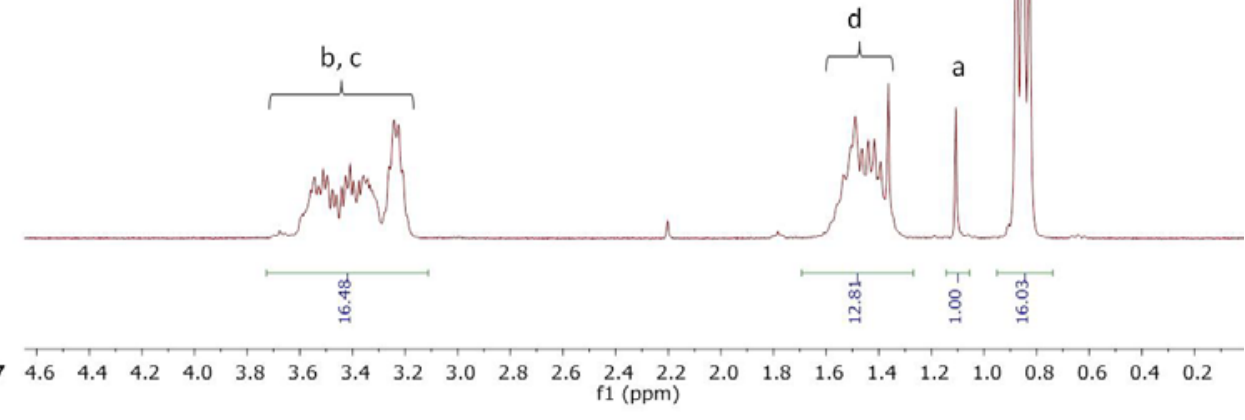

Figure S4. SEC traces (left) and ${ }^{1} \mathrm{H}$ NMR spectrum in $\mathrm{CDCl}_{3}$ (right) of a poly(butylene oxide) synthesized with tert-butyl $N$-allylcarbamate $/ t \mathrm{BuP}_{4}$ as initiating system (Table 1 , run $5)$. 

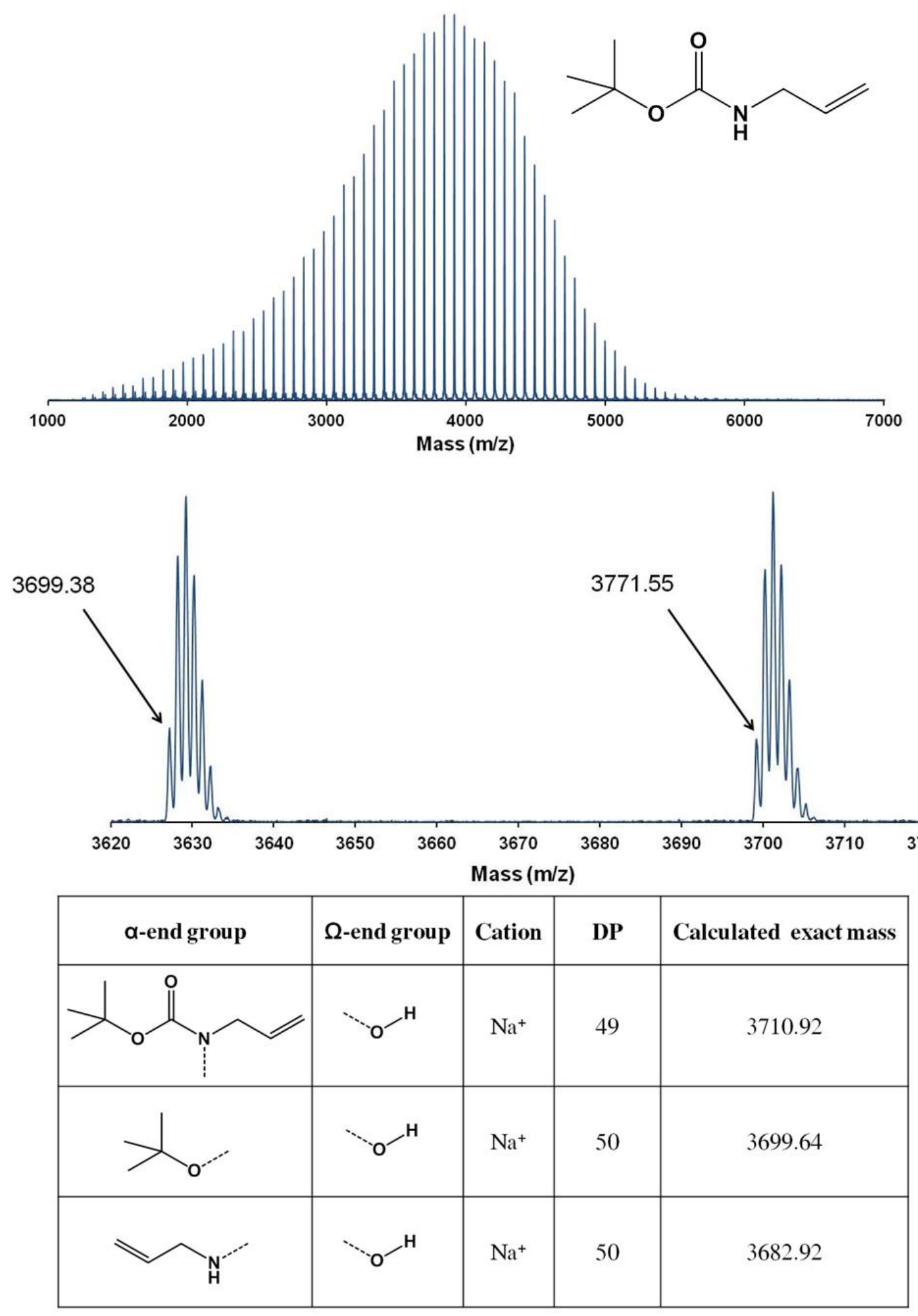

Figure S5. MALDI-ToF spectra (top: linear mode; bottom: reflectron mode) of a poly(butylene oxide) synthesized with tert-butyl $N$-allylcarbamate / $t \mathrm{BuP}_{4}$ as initiating system (Table 1, run 5). 

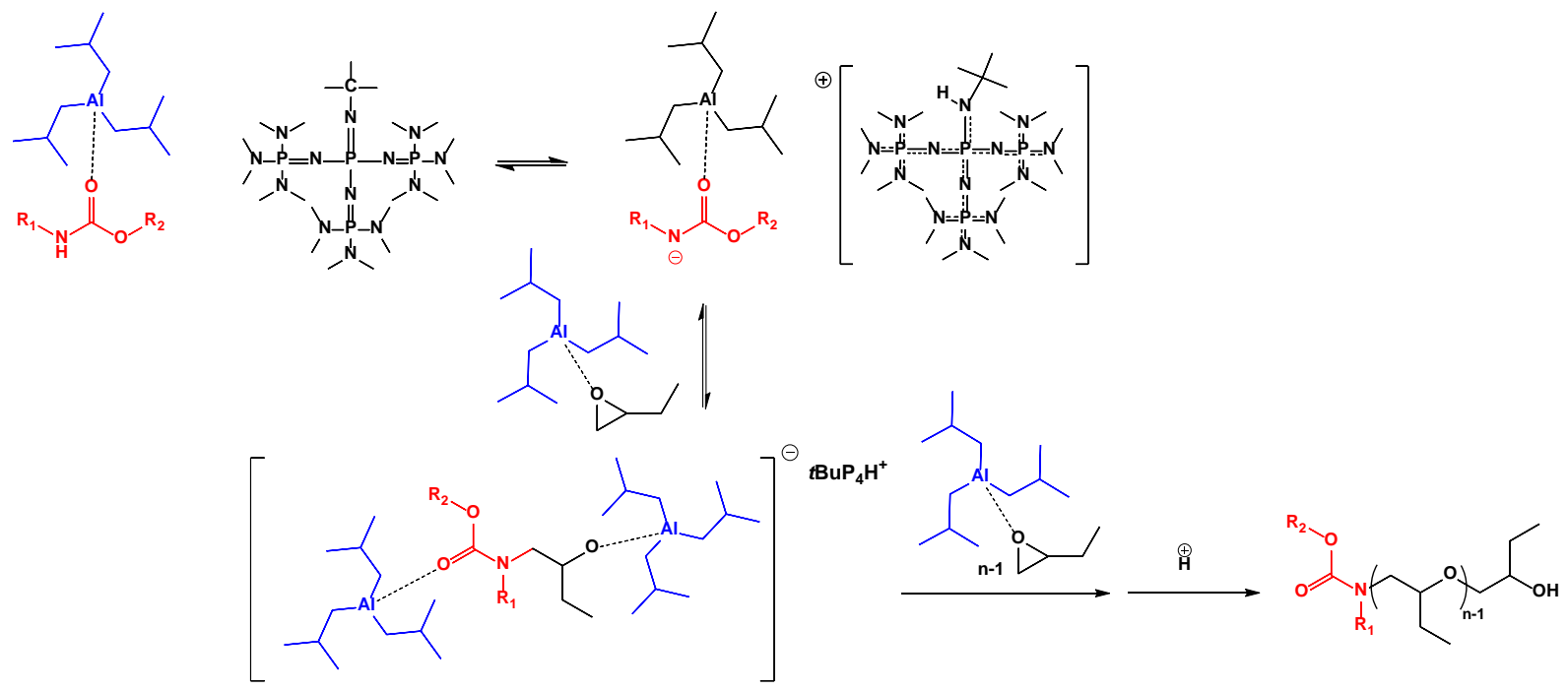

Figure S6. Postulated mechanism for the ROP of 1,2-epoxybutane using secondary urethanetriisobutylaluminum-phosphazene base (1-3-1) as initiating system.

A

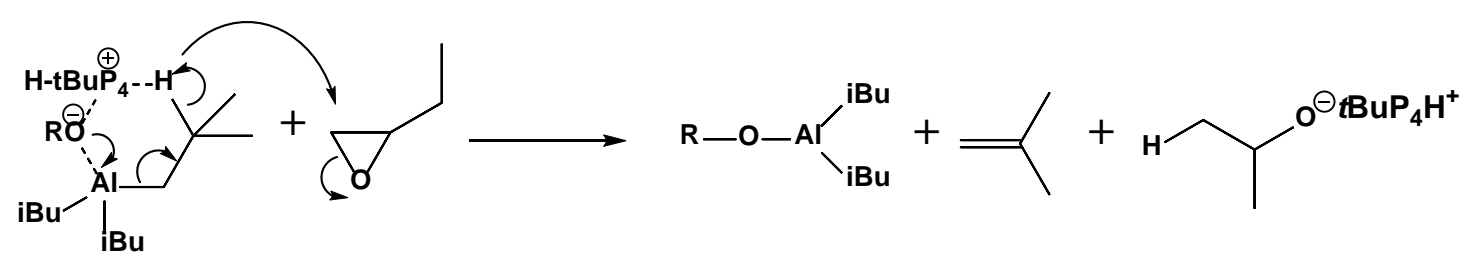

B

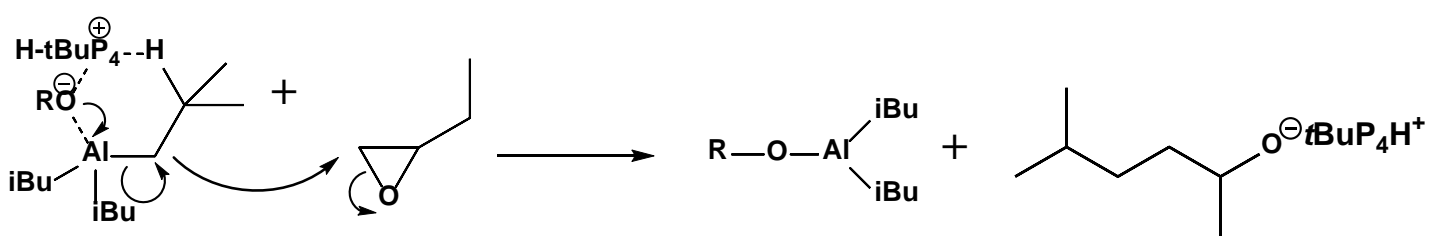

Figure S7. Proposed mechanisms for the transfer reactions during the anionic ring-opening polymerization of 1,2-epoxybutane in presence of triisobutylaluminum. 


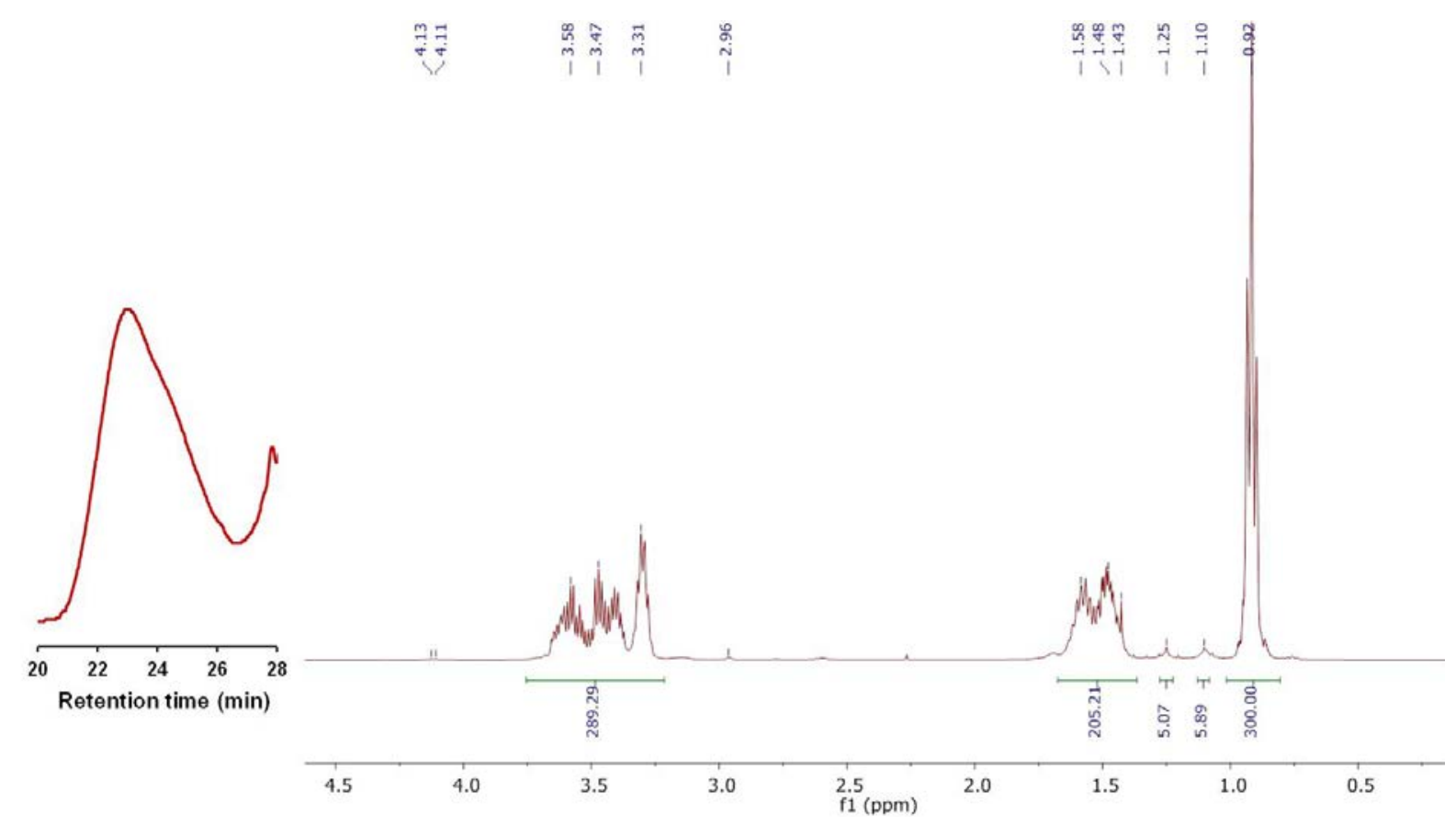

Figure S8. SEC traces (left) and ${ }^{1} \mathrm{H}$ NMR spectrum in $\mathrm{CDCl}_{3}$ (right) of a poly(butylene oxide) synthesized with $N$-methylurethane / $i \mathrm{Bu}_{3} \mathrm{Al} / t \mathrm{BuP}_{4}(1 / 3 / 1)$ as initiating system (Table 2, run 1). 

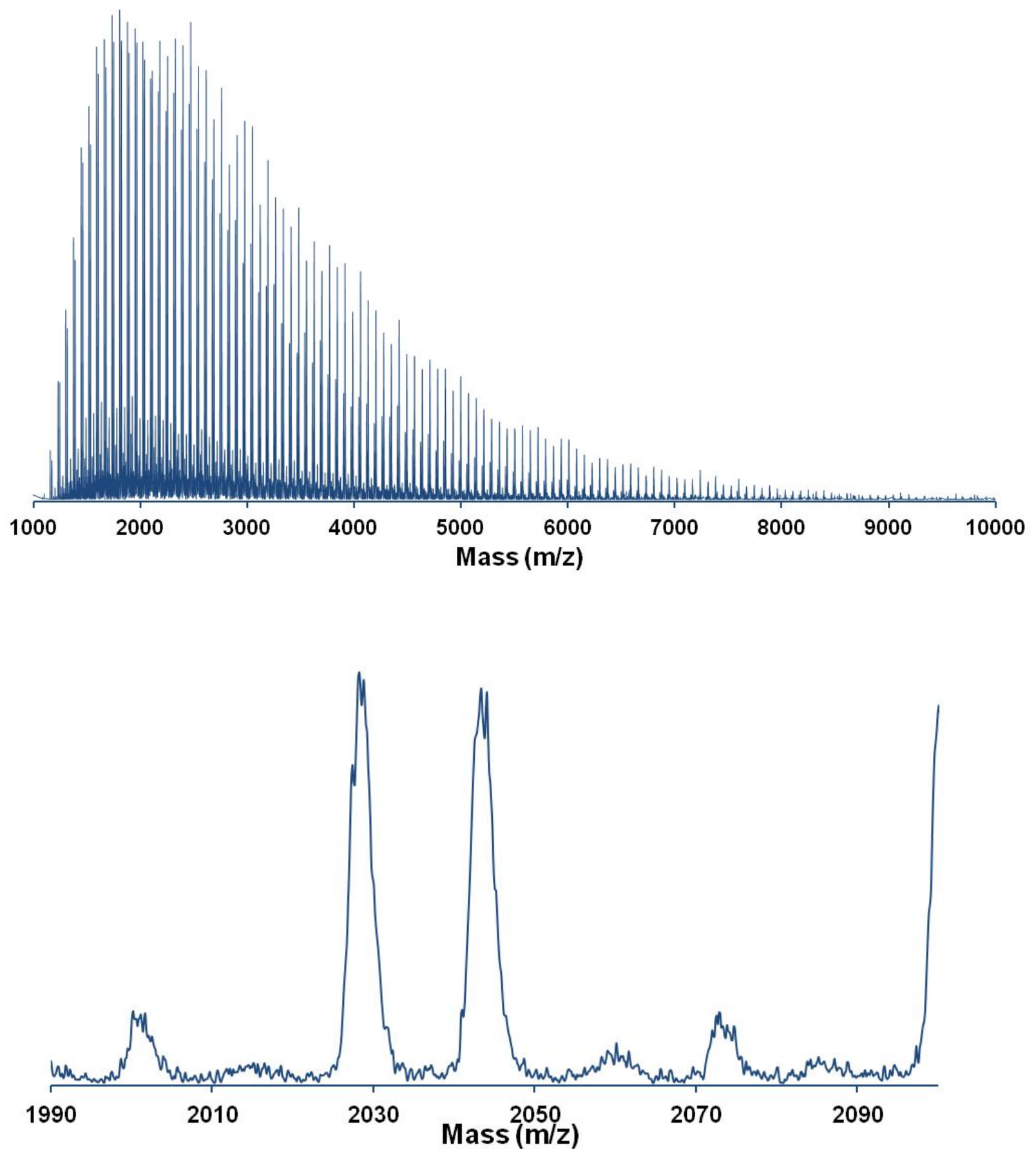

Figure S9. MALDI-ToF spectra (linear mode) of a poly(butylene oxide) synthesized with $N$ methylurethane / $i \mathrm{Bu}_{3} \mathrm{Al} / t \mathrm{BuP}_{4}(1 / 3 / 1)$ as initiating system in toluene (Table 2, run 1). 


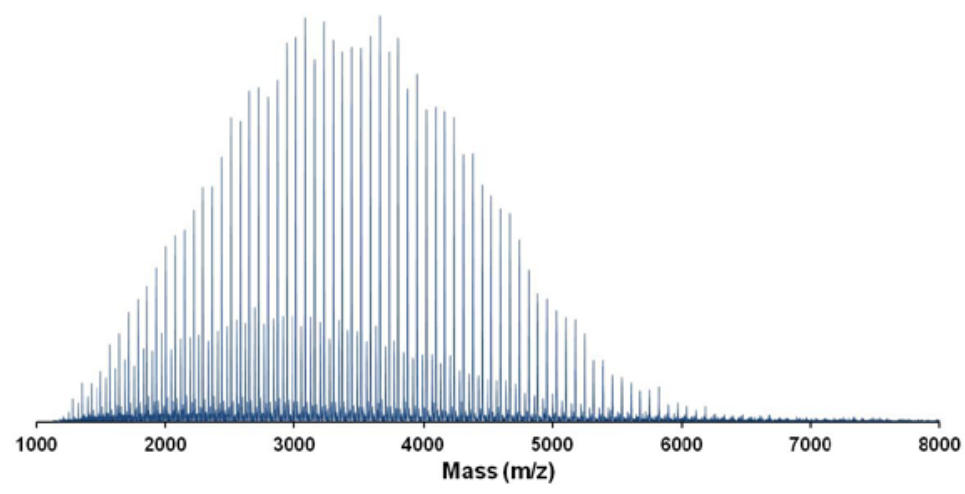

Figure S10. MALDI-ToF spectra (linear mode) of a poly(butylene oxide) synthesized with $N$ methylurethane / ${ }_{\mathrm{i}} \mathrm{Bu}_{3} \mathrm{Al} / t \mathrm{BuP}_{4}(1 / 1 / 1)$ as initiating system in toluene (Table 2, run 2).
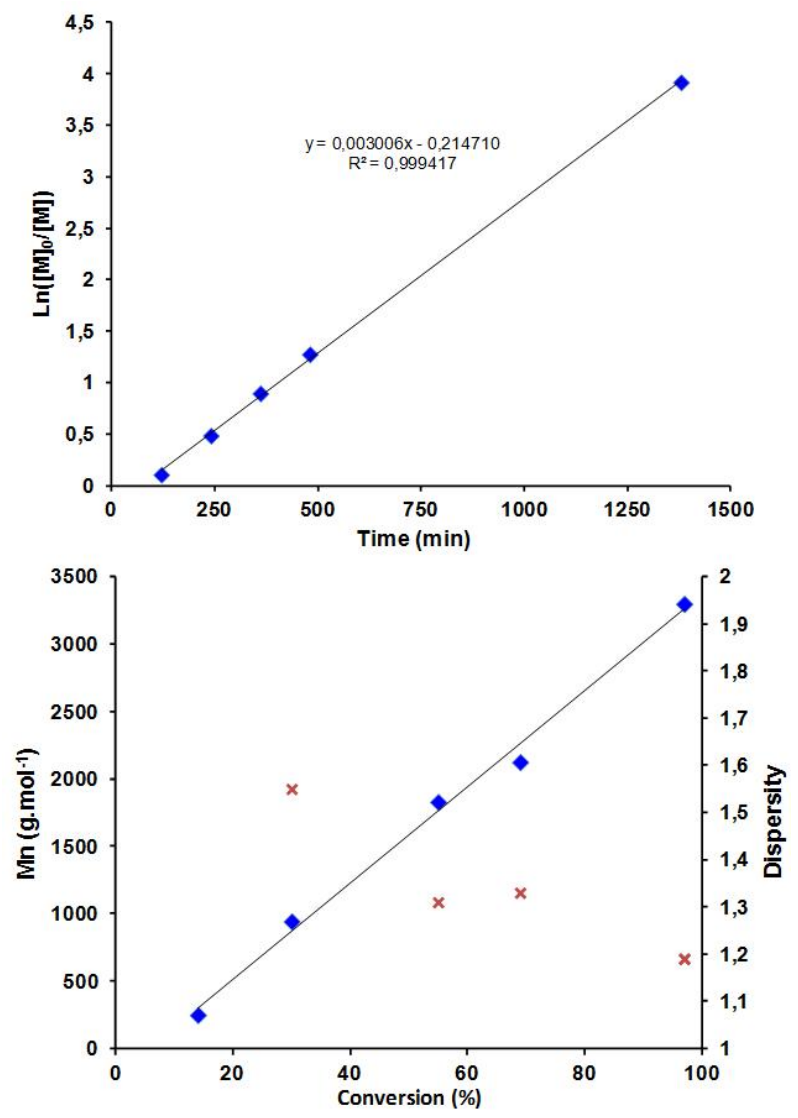

Figure S11. Anionic ring-opening polymerization of 1,2-epoxybutane synthesized with $\mathrm{N}$ methylurethane $/ i \mathrm{Bu}_{3} \mathrm{Al} / t \mathrm{BuP}_{4}$ as initiating system in toluene (Table 2, run 2) at $25{ }^{\circ} \mathrm{C}$ in toluene $\left([\mathrm{I}]_{0}=0.06534 \mathrm{~mol} . \mathrm{L}^{-1},[\mathrm{M}]_{0}=3.27 \mathrm{~mol} . \mathrm{L}^{-1}\right.$, M: $N$-methylurethane: $i \mathrm{Bu}_{3} \mathrm{Al}: t \mathrm{BuP}_{4}=$ 50:1:1:1:1): (a) first-order kinetic plot ; (b) relationship observed between number-average molar mass (squares; linear trend is indicated by the dashed line) or dispersity (crosses) and monomer conversion. 


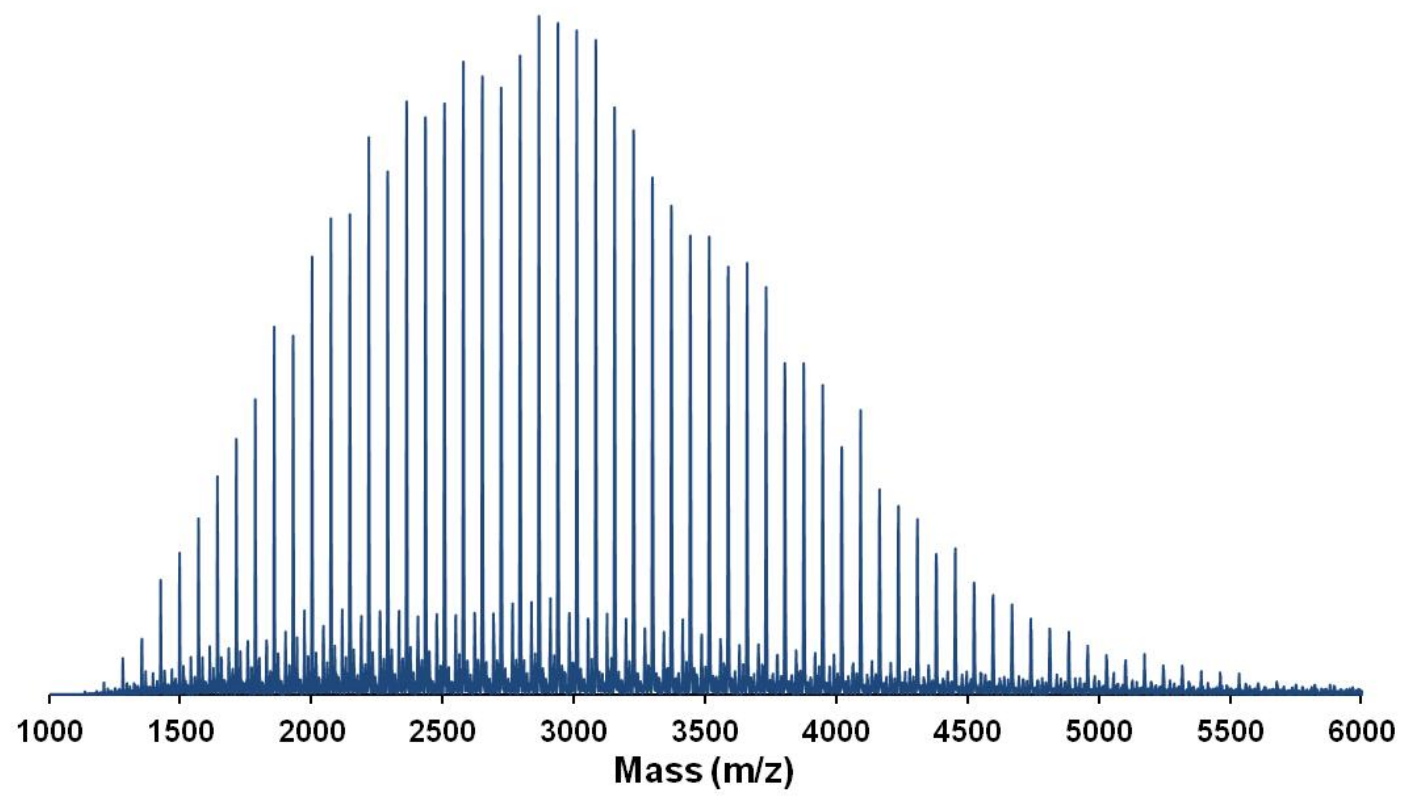

Figure S12. MALDI-ToF spectra (linear mode) of a poly(butylene oxide) synthesized with $N$ methylurethane / ${ }_{\mathrm{i}} \mathrm{Bu}_{3} \mathrm{Al} / t \mathrm{BuP}_{2}(1 / 1 / 1)$ as initiating system in toluene (Table 2, run 3).

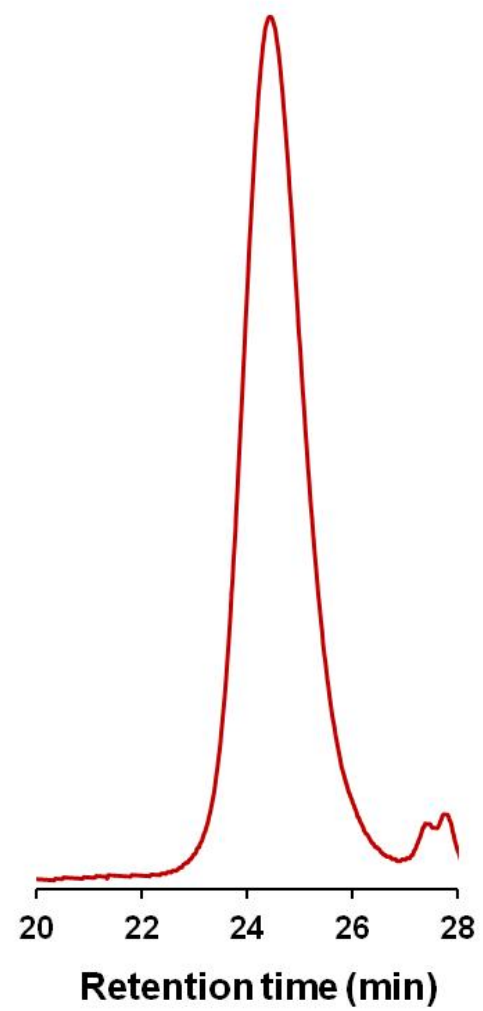

Figure S13. SEC trace of a poly(butylene oxide) synthesized with $N$-methylurethane / ${ }_{i} \mathrm{Bu}_{3} \mathrm{Al} / t \mathrm{BuP}_{2}(1 / 1 / 1)$ as initiating system in toluene (Table 2, run 3). 


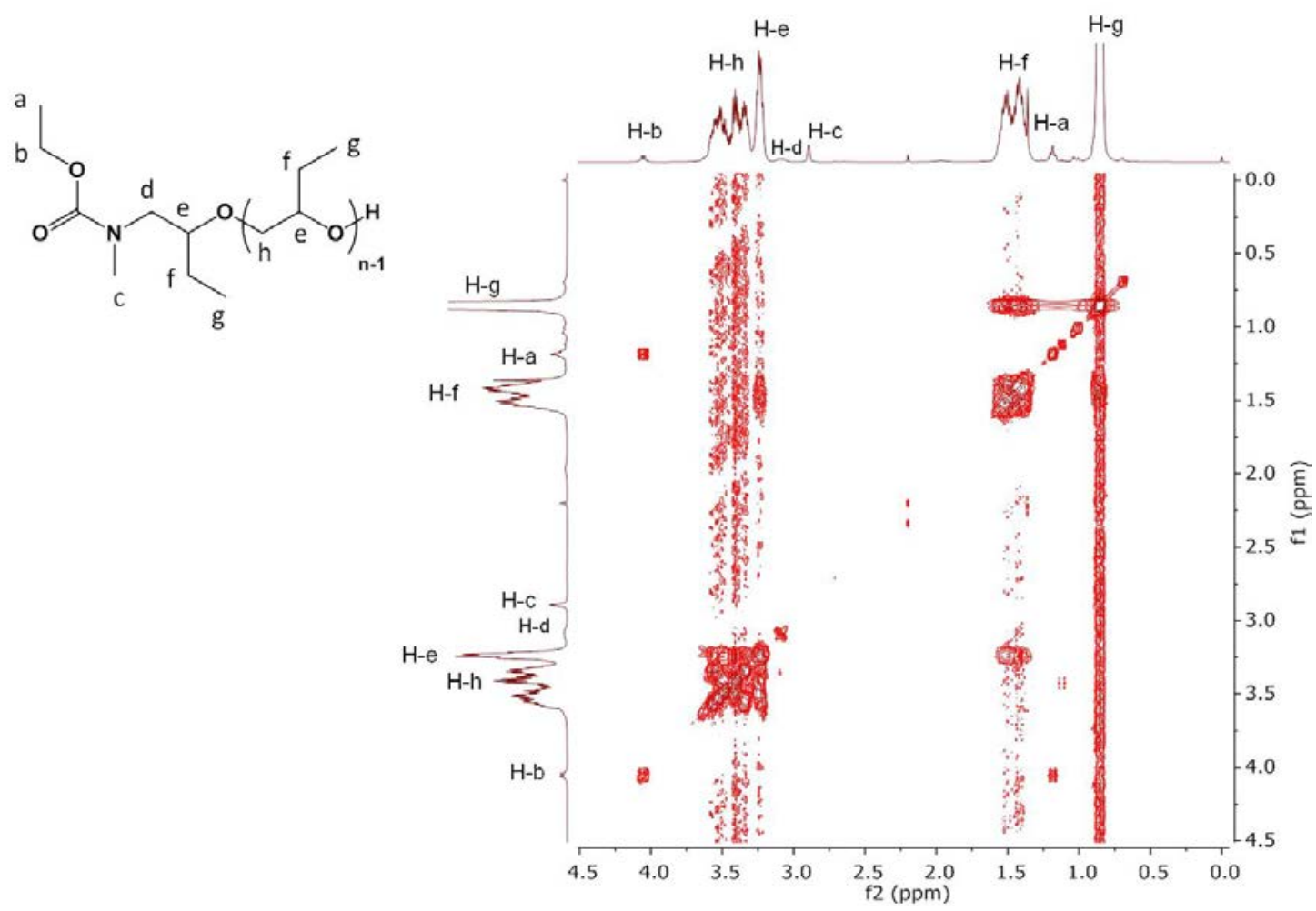

Figure S14. 2D COSY-NMR spectrum in $\mathrm{CDCl}_{3}$ at room temperature of a poly(butylene oxide) synthesized with $N$-methylurethane / ${ }_{i} \mathrm{Bu}_{3} \mathrm{Al} / t \mathrm{BuP}_{2}(1 / 1 / 1)$ as initiating system in toluene (Table 2, run 3).

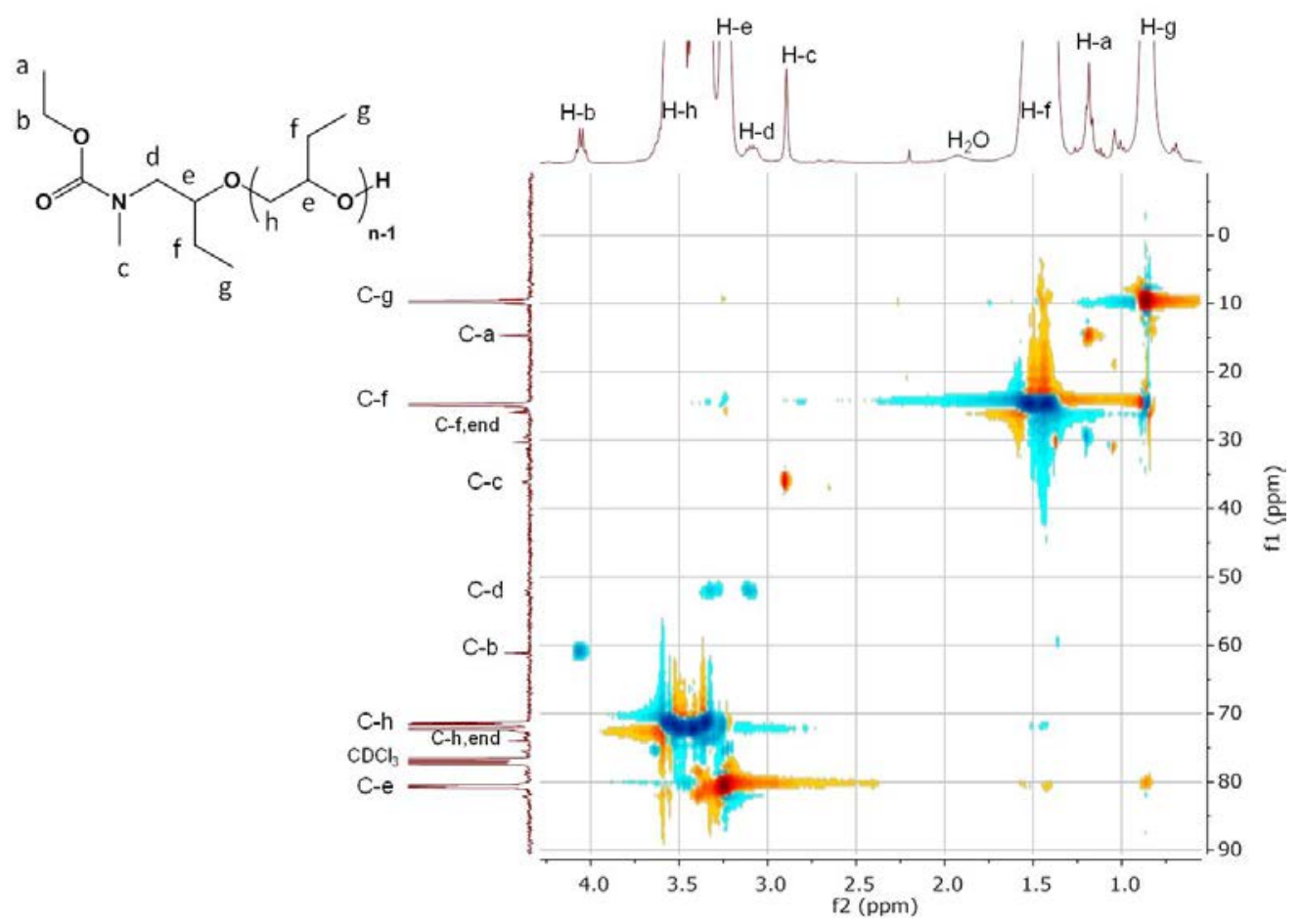

Figure S15. 2D HSQC-NMR spectrum in $\mathrm{CDCl}_{3}$ at room temperature of a poly(butylene oxide) synthesized with $N$-methylurethane / ${ }_{i} \mathrm{Bu}_{3} \mathrm{Al} / t \mathrm{BuP}_{2}(1 / 1 / 1)$ as initiating system in toluene (Table 2, run 3). 


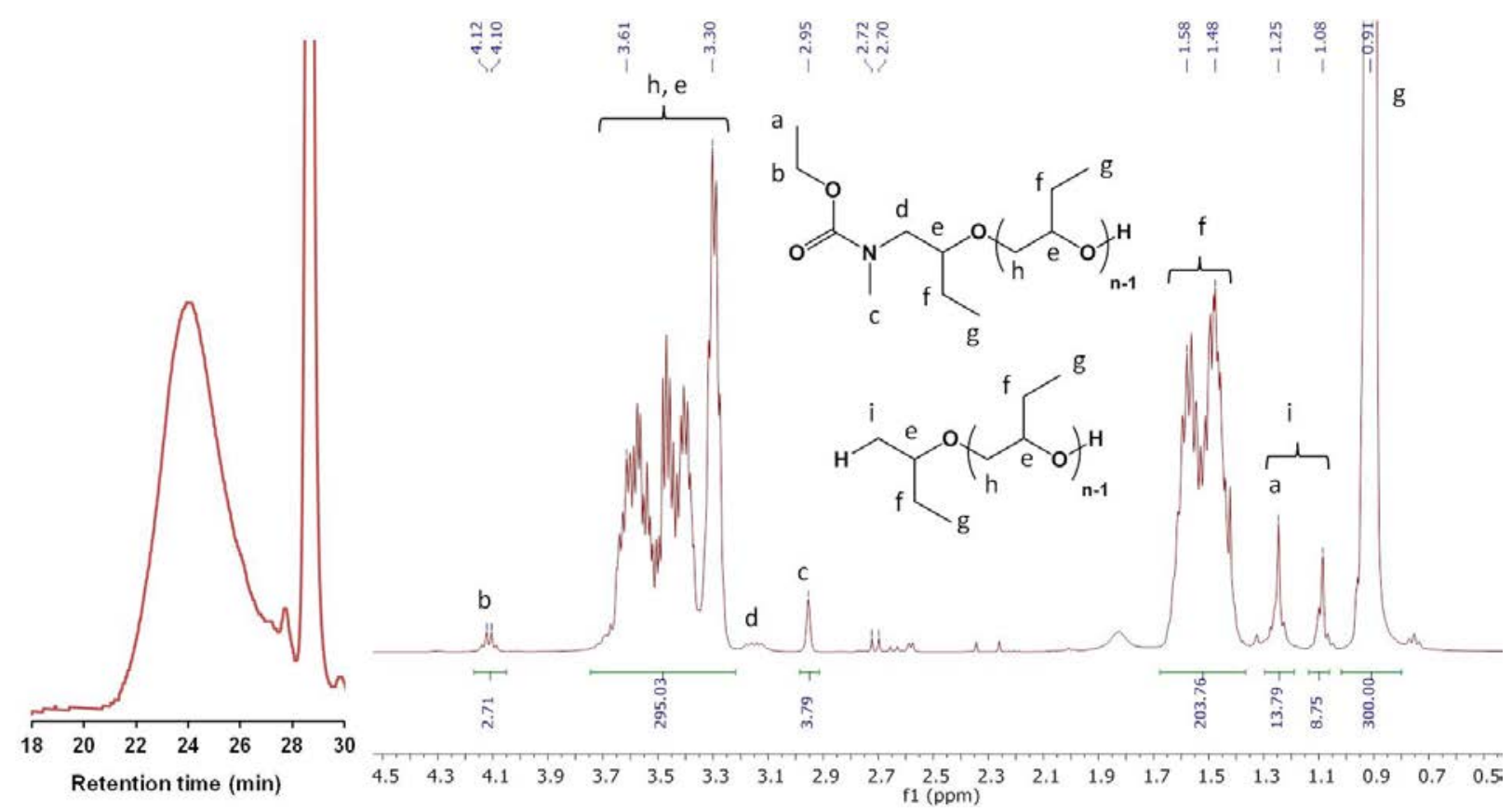

Figure S16. SEC traces (left) and ${ }^{1} \mathrm{H}$ NMR spectrum in $\mathrm{CDCl}_{3}$ (right) of a poly(butylene oxide) synthesized with $N$-methylurethane / $i \mathrm{Bu}_{3} \mathrm{Al} / t \mathrm{BuP}_{4}(1 / 3 / 1)$ as initiating system in MeTHF (Table 2, run 4).

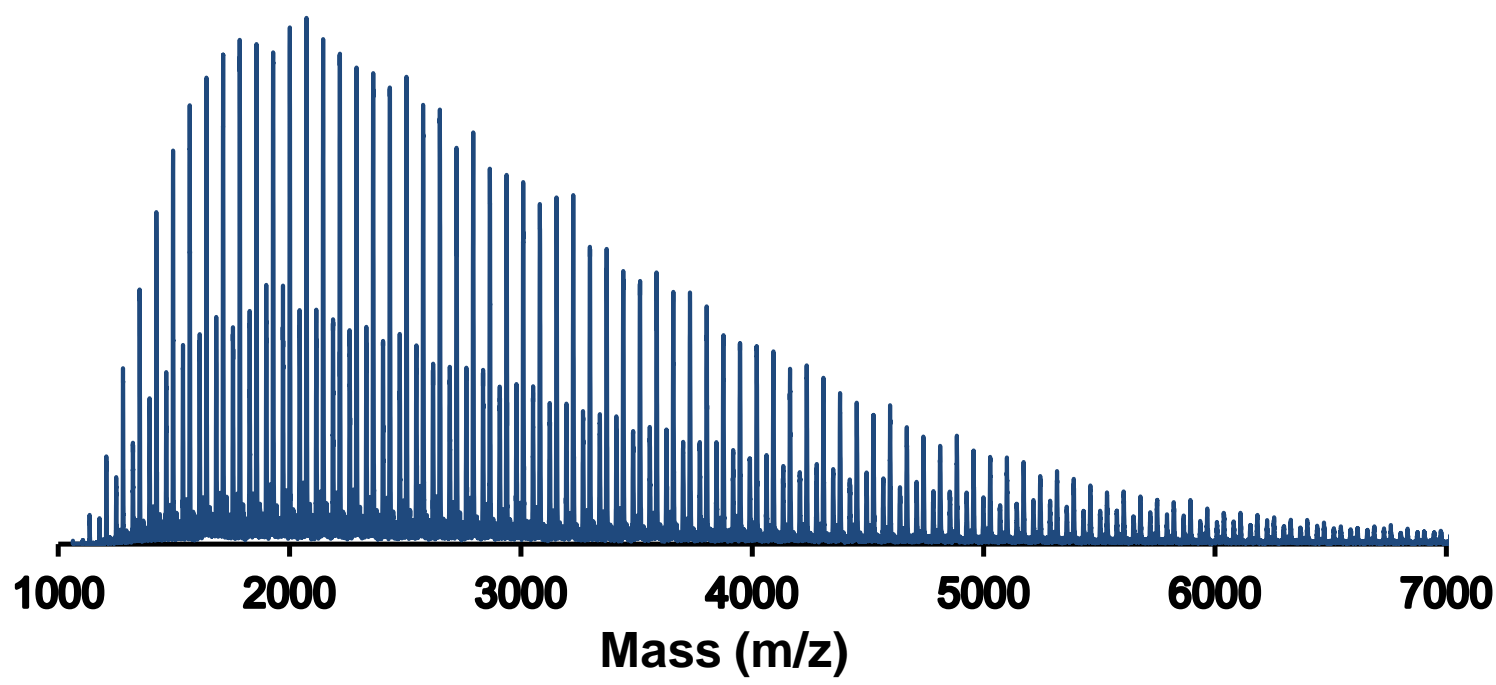

Figure S17. MALDI-ToF spectra (linear mode) of a poly(butylene oxide) synthesized with $N$ methylurethane / $i \mathrm{Bu}_{3} \mathrm{Al} / t \mathrm{BuP}_{4}(1 / 3$ / 1) as initiating system in MeTHF (Table 2, run 4). 

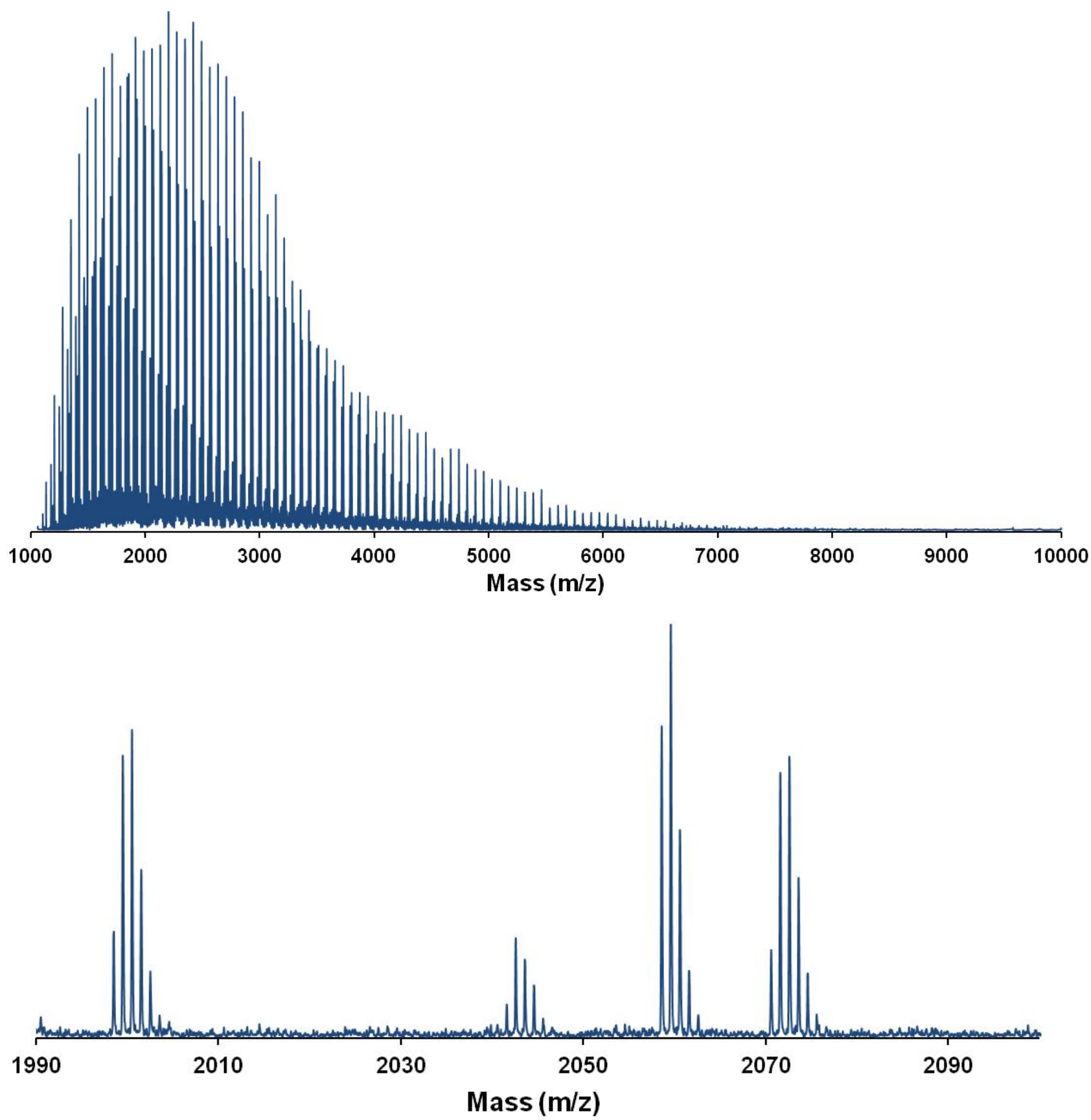

Figure S18. MALDI-ToF spectra (top: linear mode; bottom: reflectron mode) of a poly(butylene oxide) synthesized with $N$-methylurethane / $i \mathrm{Bu}_{3} \mathrm{Al} / t \mathrm{BuP}_{4}(1 / 3 / 1)$ as initiating system in MeTHF (Table 2, run 6). 


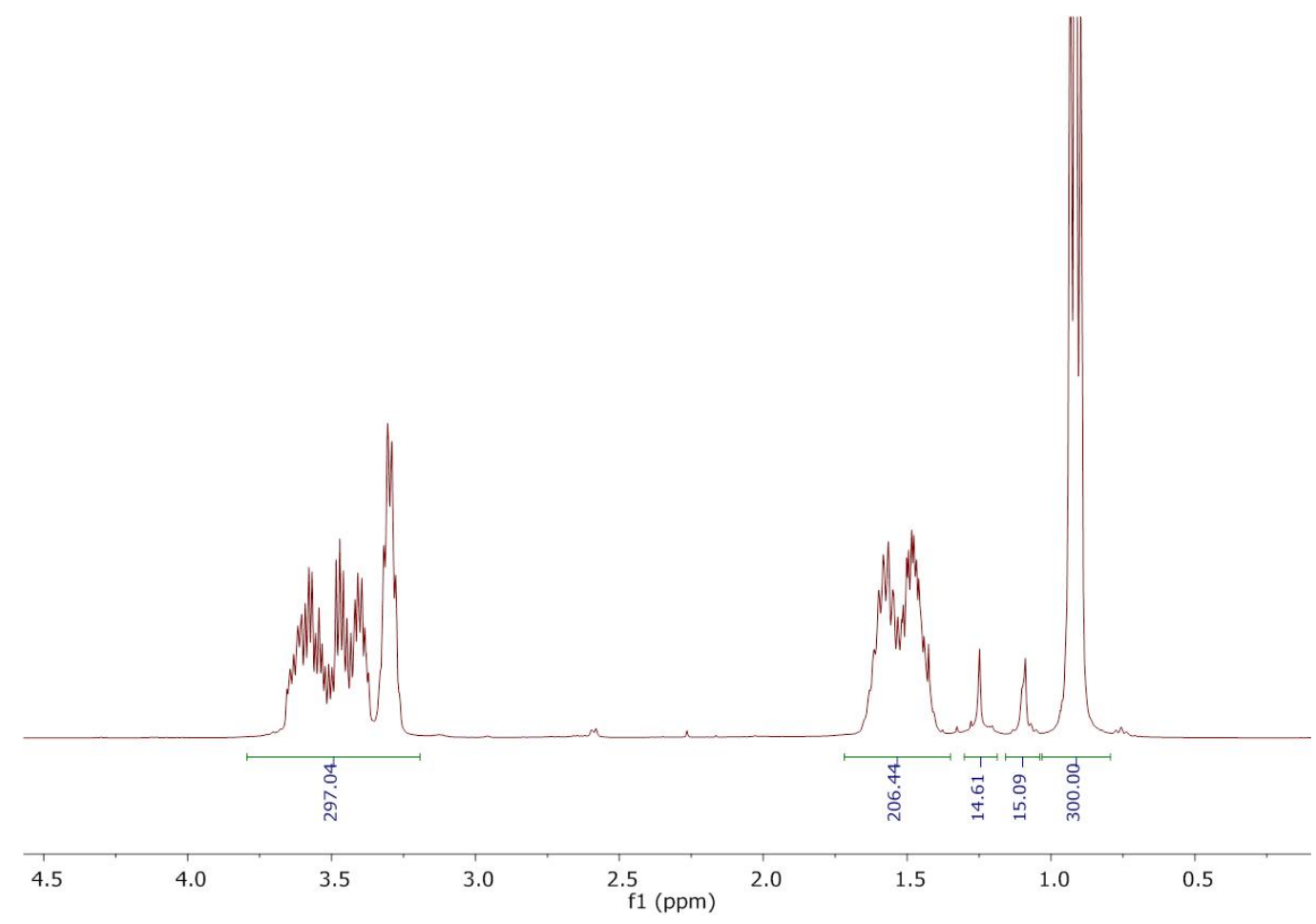

Figure S19. ${ }^{1} \mathrm{H}$ NMR spectrum in $\mathrm{CDCl}_{3}$ of a poly(butylene oxide) synthesized with $\mathrm{N}$ methylurethane / $i \mathrm{Bu}_{3} \mathrm{Al} / \mathrm{tBuP} 4(1 / 3$ / 1) as initiating system in MeTHF (Table 2, run 7). 

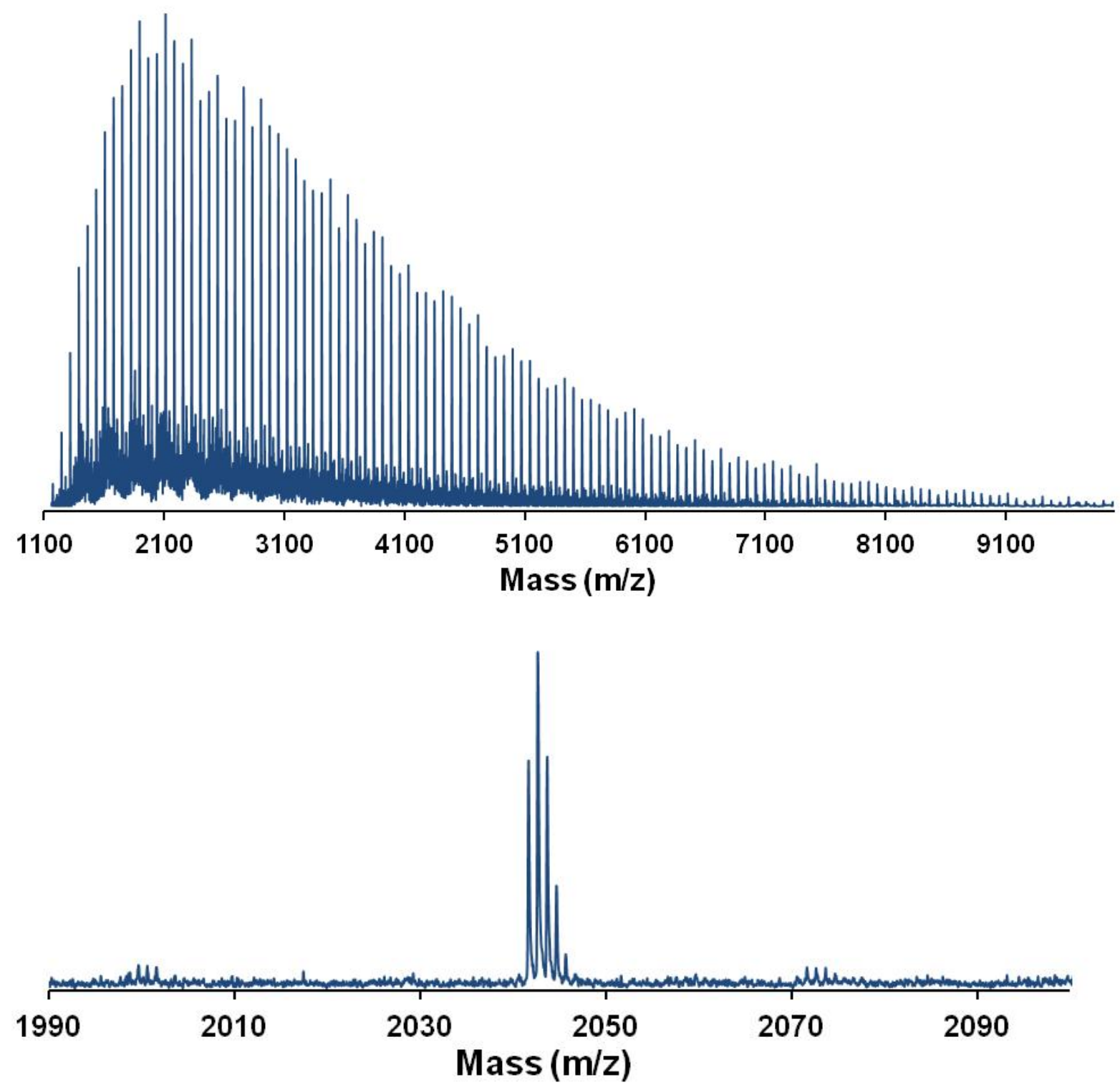

Figure S20. MALDI-ToF spectra (top: linear mode; bottom: reflectron mode) of a poly(butylene oxide) synthesized with $N$-methylurethane / $i \mathrm{Bu}_{3} \mathrm{Al} / t \mathrm{BuP}_{4}(1 / 3 / 1)$ as initiating system in MeTHF (Table 2, run 7). 

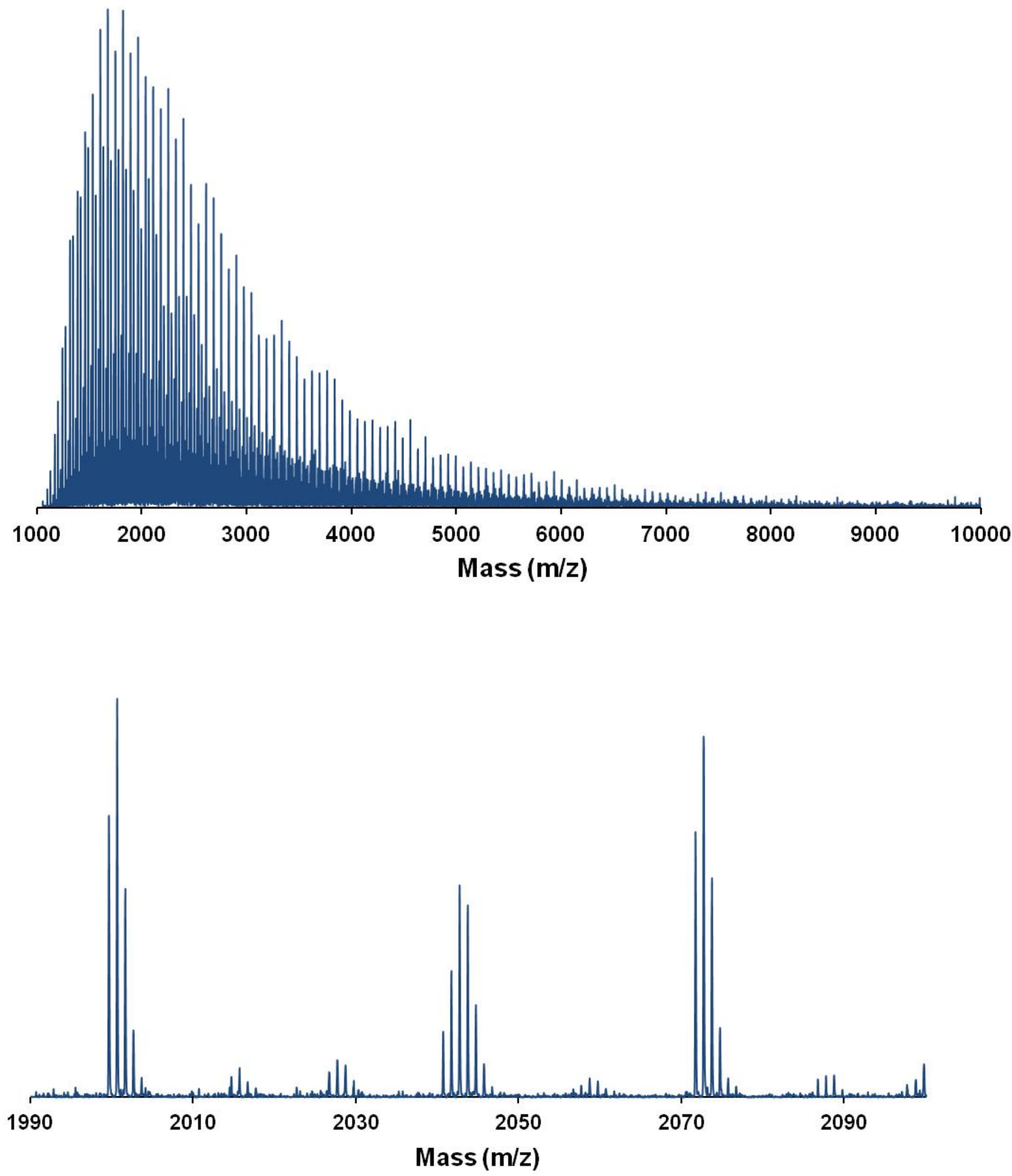

Figure S21. MALDI-ToF spectra (top: linear mode; bottom: reflectron mode) of a poly(butylene oxide) synthesized with $N$-methylurethane / $i \mathrm{Bu}_{3} \mathrm{Al} / t \mathrm{BuP}_{4}(1 / 3 / 1)$ as initiating system in MeTHF (Table 2, run 8). 


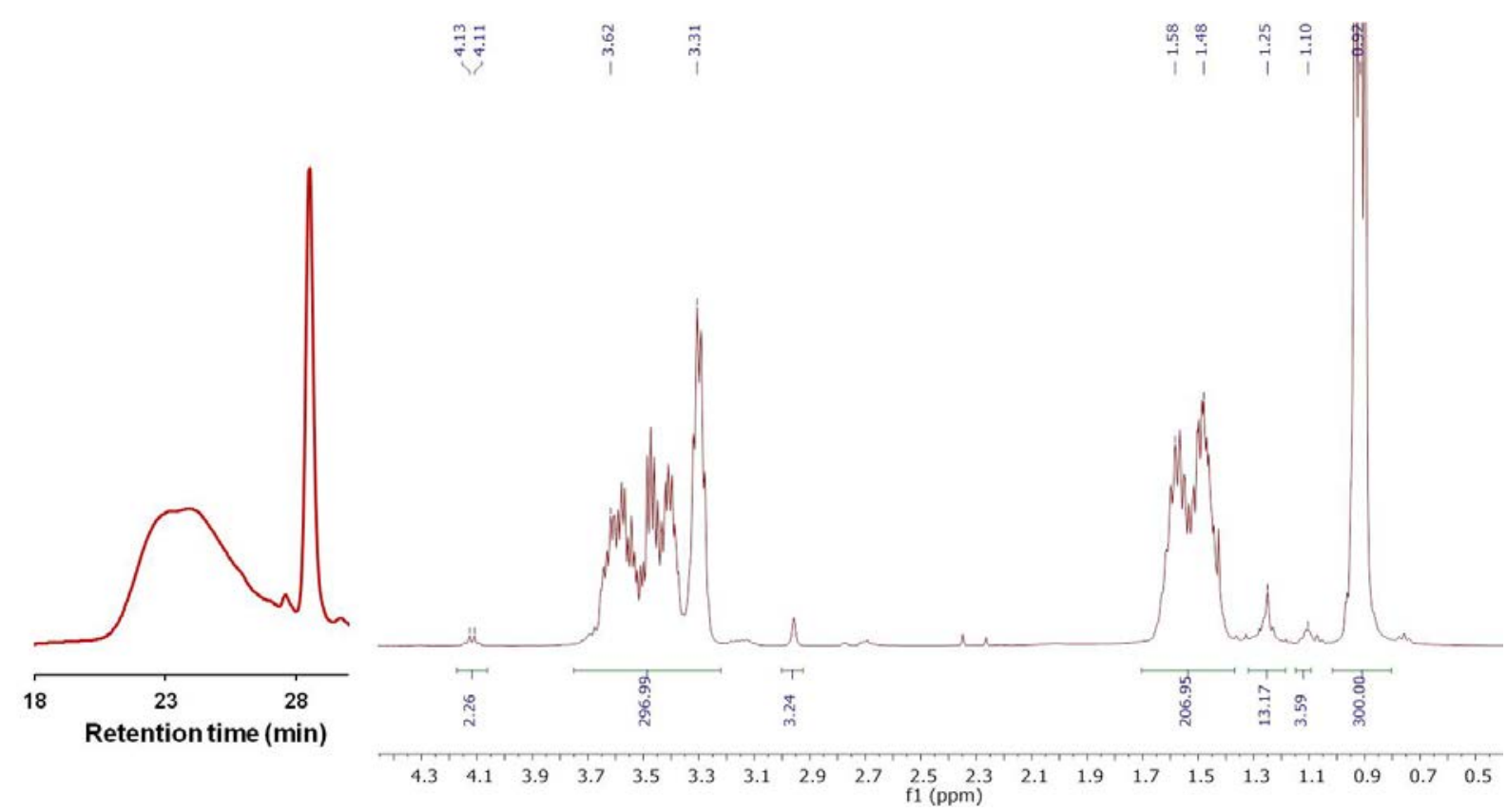

Figure S22. SEC traces (left) and ${ }^{1} \mathrm{H}$ NMR spectrum in $\mathrm{CDCl}_{3}$ (right) of a poly(butylene oxide) synthesized with $N$-methylurethane / $\mathrm{Buu}_{3} \mathrm{Al} / t \mathrm{BuP}_{2}(1 / 3 / 1)$ as initiating system in MeTHF (Table 2, run 9).
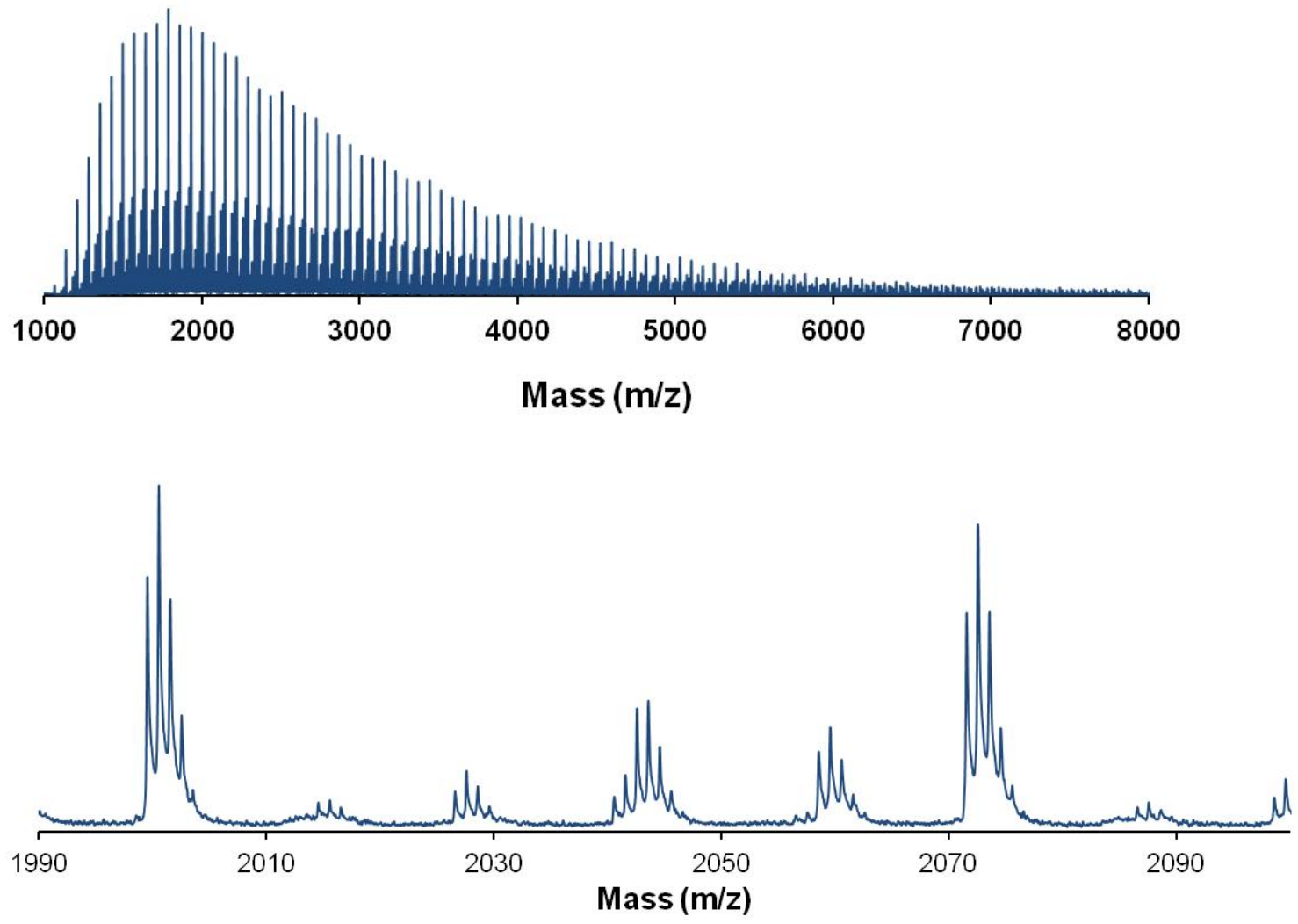

Figure S23. MALDI-ToF spectra (top: linear mode; bottom: reflectron mode) of a poly(butylene oxide) synthesized with $N$-methylurethane / $i \mathrm{Bu}_{3} \mathrm{Al} / t \mathrm{BuP}_{2}(1 / 3 / 1)$ as initiating system in MeTHF (Table 2, run 9). 


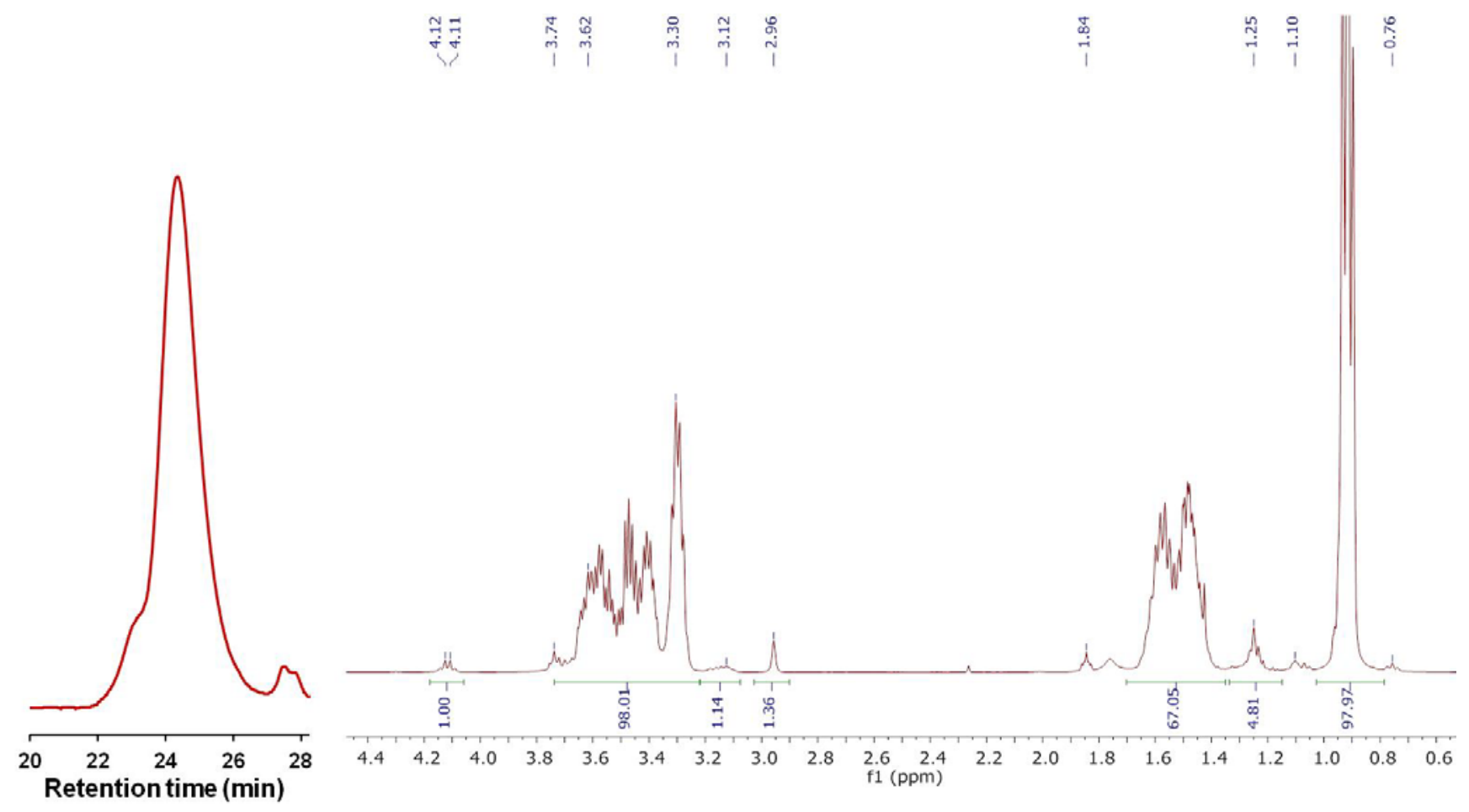

Figure S24. SEC traces (left) and ${ }^{1} \mathrm{H}$ NMR spectrum in $\mathrm{CDCl}_{3}$ (right) of a poly(butylene oxide) synthesized with $N$-methylurethane / $\mathrm{BBu}_{3} \mathrm{Al} / t \mathrm{BuP}_{4}(1 / 1 / 1)$ as initiating system in MeTHF (Table 2, run 11). 

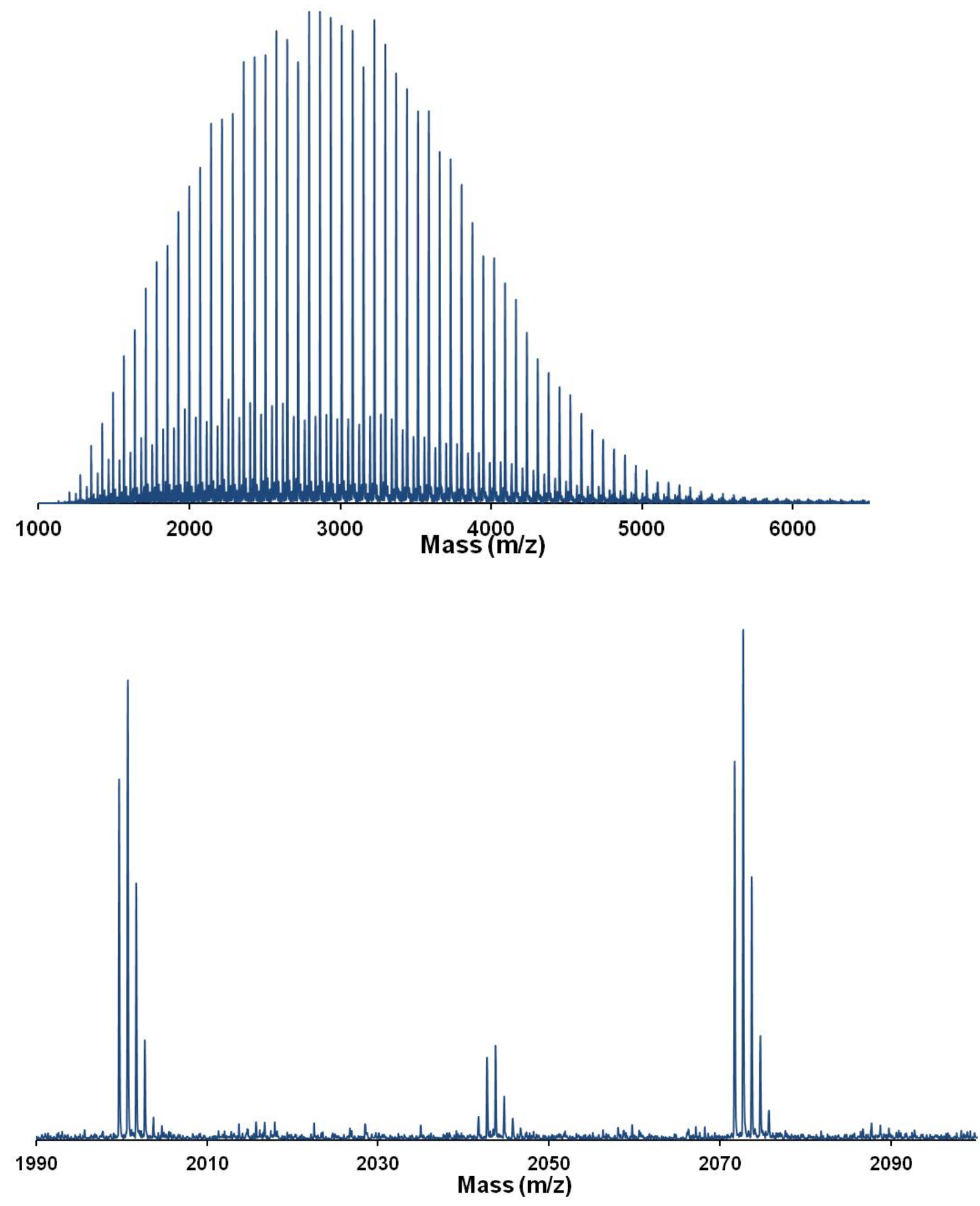

Figure S25. MALDI-ToF spectra (top: linear mode; bottom: reflectron mode) of a poly(butylene oxide) synthesized with $N$-methylurethane / $i \mathrm{Bu}_{3} \mathrm{Al} / t \mathrm{BuP}_{4}(1 / 1 / 1)$ as initiating system in MeTHF (Table 2, run 11). 


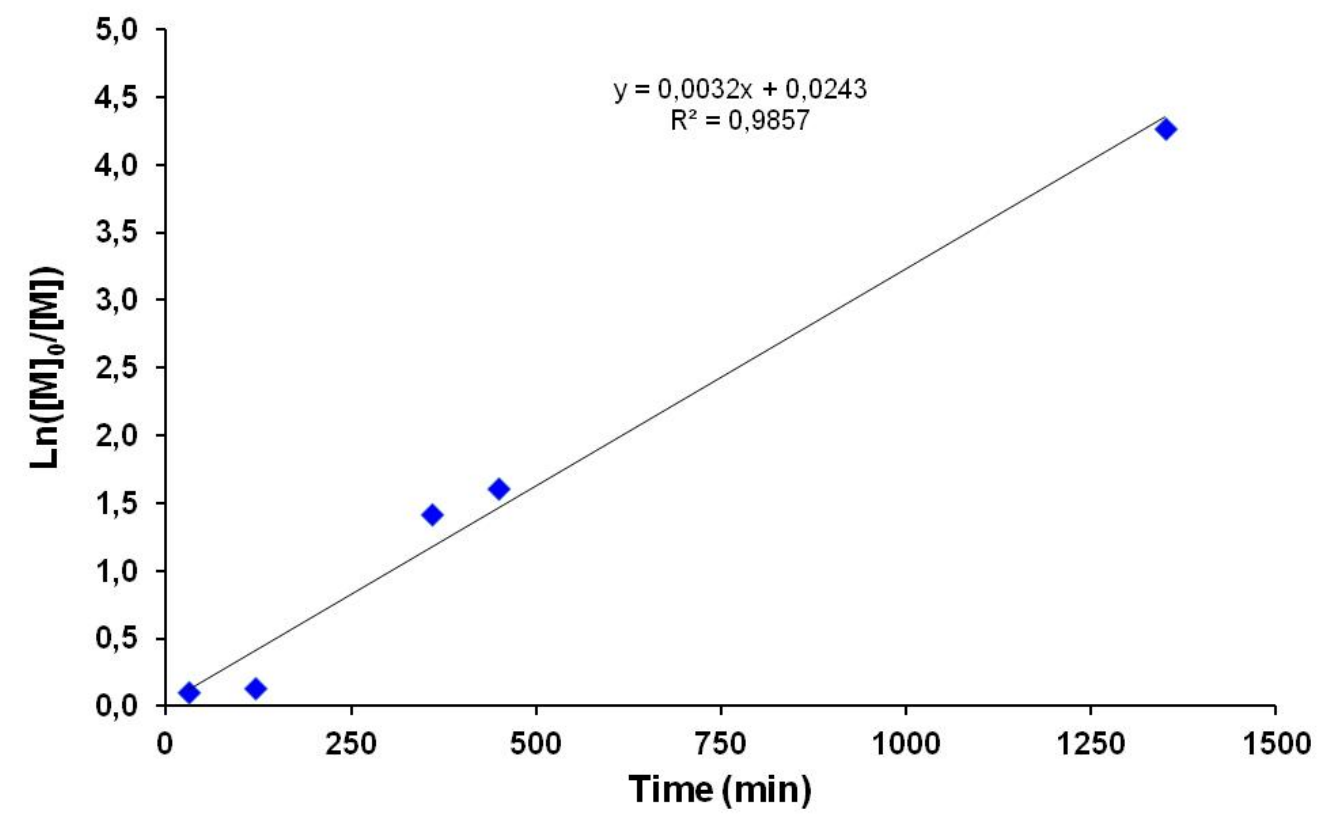

Figure S26. Anionic ring-opening polymerization of 1,2-epoxybutane synthesized with $\mathrm{N}$ methylurethane / $i \mathrm{Bu}_{3} \mathrm{Al} / \mathrm{tBuP} \mathrm{Bu}_{4}$ as initiating system in MeTHF (Table 2, run 11) at $25^{\circ} \mathrm{C}$ $\left([\mathrm{I}]_{0}=0.065\right.$ mol. $\mathrm{L}^{-1},[\mathrm{M}]_{0}=3.27 \mathrm{~mol} . \mathrm{L}^{-1}, \mathrm{M}: N$-methylurethane:iBu$\left.{ }_{3} \mathrm{Al}: t \mathrm{BuP}_{4}=50: 1: 1: 1\right)$ : first-order kinetic plot (slope $=0.0032 \mathrm{~min}^{-1}, \mathrm{R}^{2}=0.986$ ). 


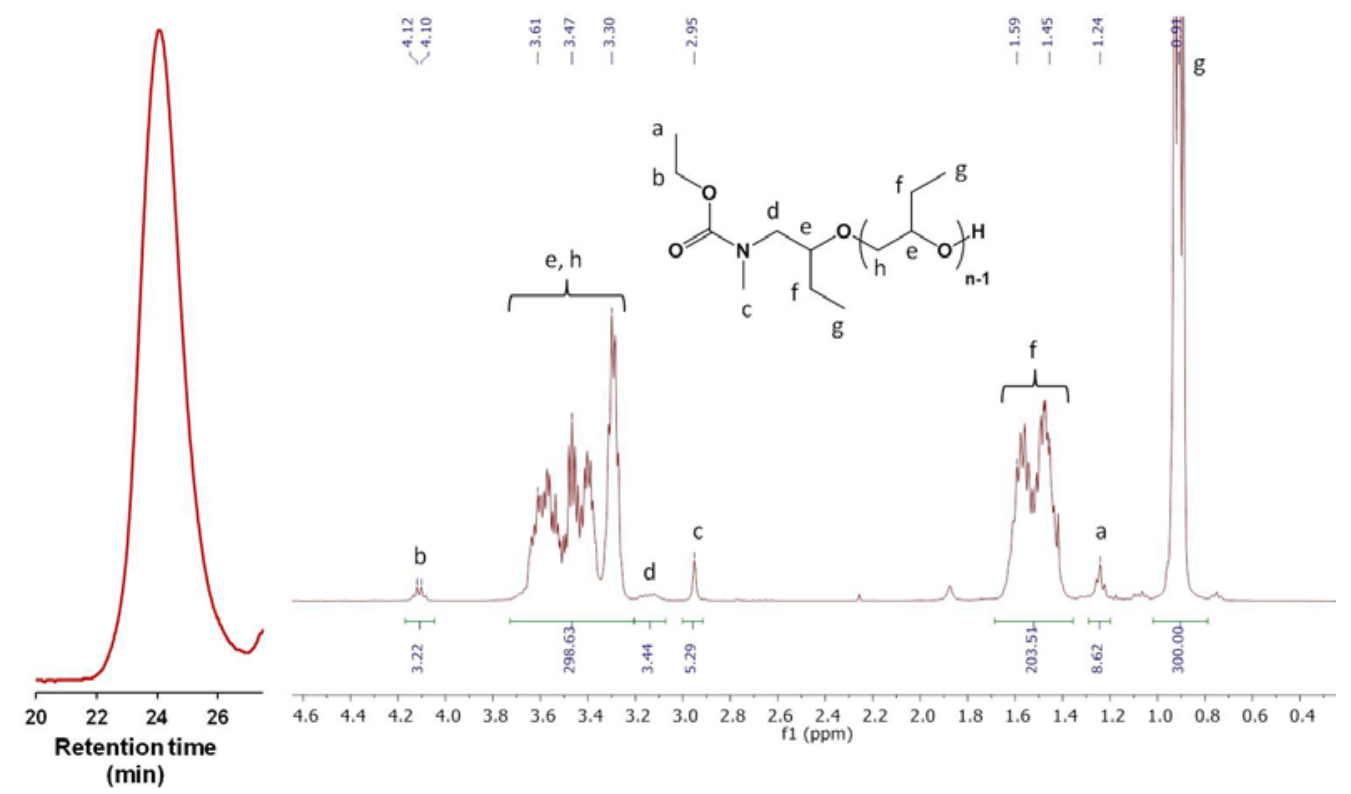

Figure S27. SEC traces (left) and ${ }^{1} \mathrm{H}$ NMR spectrum in $\mathrm{CDCl}_{3}$ (right) of a poly(butylene oxide) synthesized with $N$-methylurethane / $\mathrm{BBu}_{3} \mathrm{Al} / t \mathrm{BuP}_{2}(1 / 1 / 1)$ as initiating system in MeTHF (Table 2, run 12).
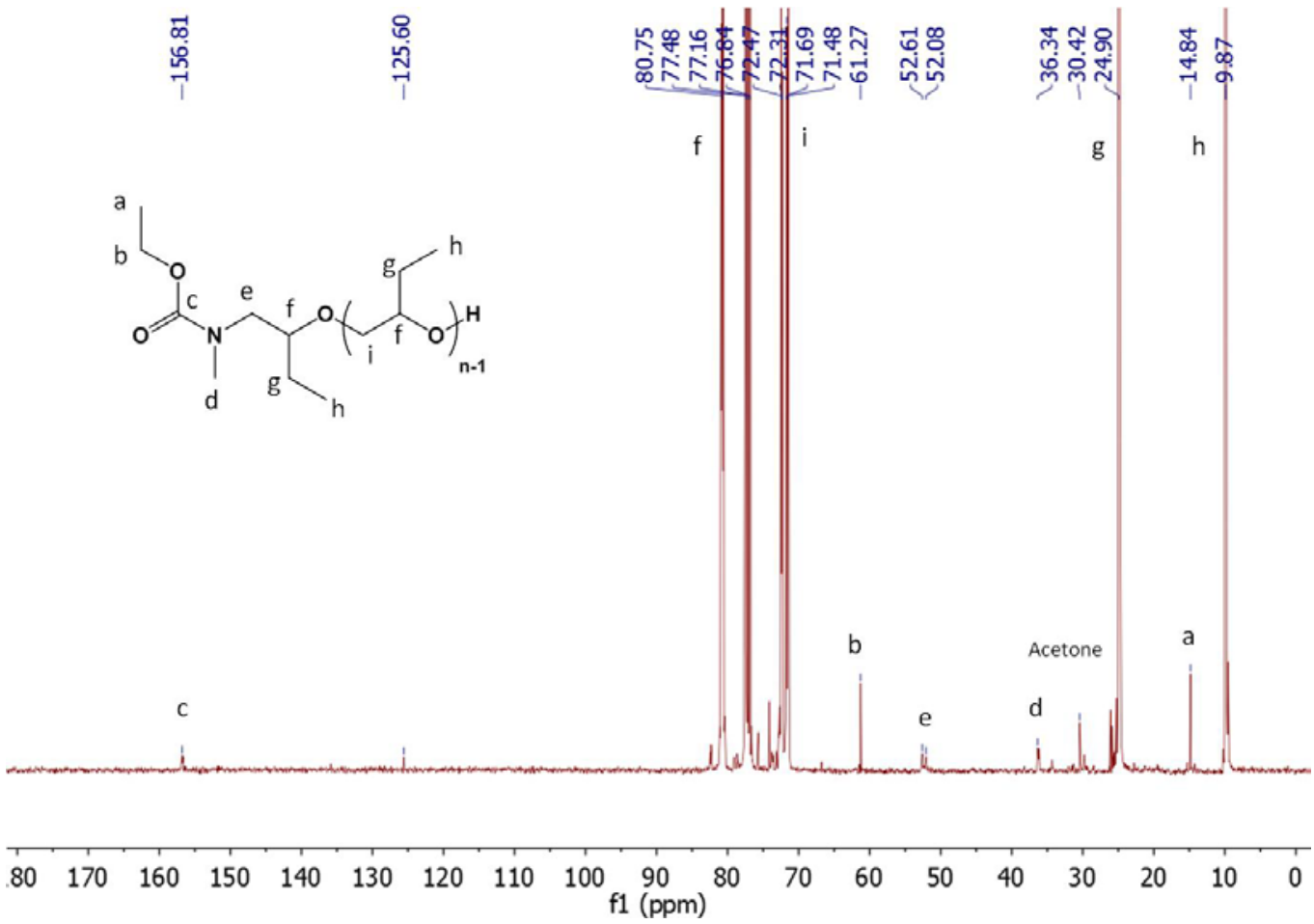

Figure S28. ${ }^{13} \mathrm{C}$ NMR spectrum in $\mathrm{CDCl}_{3}$ of a poly(butylene oxide) synthesized with $\mathrm{N}$ methylurethane / $i \mathrm{Bu}_{3} \mathrm{Al} / t \mathrm{BuP}_{2}(1 / 1 / 1)$ as initiating system in MeTHF (Table 2, run 12). 

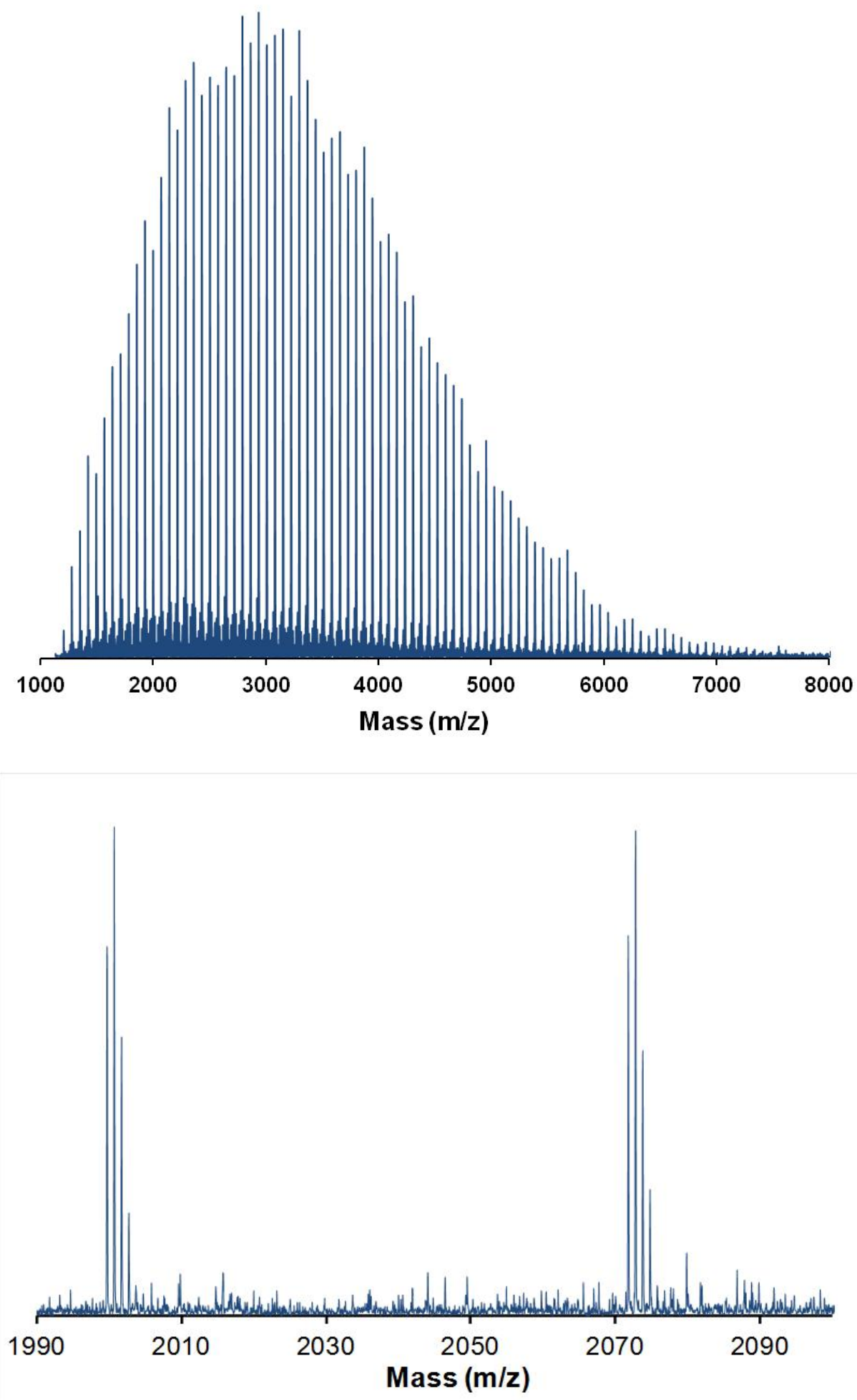

Figure S29. MALDI-ToF spectra (top: linear mode; bottom: reflectron mode) of a poly(butylene oxide) synthesized with $N$-methylurethane / $i \mathrm{Bu}_{3} \mathrm{Al} / t \mathrm{BuP}_{2}(1 / 1 / 1)$ as initiating system in MeTHF (Table 2, run 12). 